\title{
Urban Surface Temperature Reduction via the Urban Aerosol Direct Effect: A Remote Sensing and WRF Model Sensitivity Study
}

\author{
Menglin Jin, ${ }^{1}$ J. Marshall Shepherd, ${ }^{2}$ and Weizhong Zheng ${ }^{3}$ \\ ${ }^{1}$ Department of Meteorology and Climate Science, San José State University, 1 Washington Square, San José, \\ CA 95192-0104, USA \\ ${ }^{2}$ Department of Geography, University of Georgia, Athens, GA 30602, USA \\ ${ }^{3}$ IMSG at Environmental Modeling Center, NOAA/NCEP, Camp Springs, MD 20746, USA \\ Correspondence should be addressed to Menglin Jin, jin@met.sjsu.edu
}

Received 9 April 2010; Revised 13 October 2010; Accepted 24 November 2010

Academic Editor: Krishnaswamy Krishnamoorthy

Copyright ( $) 2010$ Menglin Jin et al. This is an open access article distributed under the Creative Commons Attribution License, which permits unrestricted use, distribution, and reproduction in any medium, provided the original work is properly cited.

The aerosol direct effect, namely, scattering and absorption of sunlight in the atmosphere, can lower surface temperature by reducing surface insolation. By combining National Aeronautics and Space Administration (NASA) AERONET (AErosol RObotic NETwork) observations in large cities with Weather Research and Forecasting (WRF) model simulations, we find that the aerosol direct reduction of surface insolation ranges from $40-100 \mathrm{Wm}^{-2}$, depending on aerosol loading and land-atmosphere conditions. To elucidate the maximum possible effect, values are calculated using a radiative transfer model based on the top quartile of the multiyear instantaneous aerosol data observed by AERONET sites. As a result, surface skin temperature can be reduced by $1^{\circ} \mathrm{C}-2^{\circ} \mathrm{C}$ while 2-m surface air temperature reductions are generally on the order of $0.5^{\circ} \mathrm{C}-1^{\circ} \mathrm{C}$.

\section{Introduction}

The Urban Heat Island (UHI) is an anthropogenic climate change signal described when urban skin surface, canopy, or $2-\mathrm{m}$ air temperatures are higher than the temperatures in surrounding nonurban regions [1-5]. Studies spanning many decades $[3,5-8]$ have shown that urban regions are warmer than their surroundings, using both traditional insitu measurements of surface air temperature $\left(T_{\text {air }}\right)[1]$ as well as satellite remotely sensed skin temperature $\left(T_{\text {skin }},[4\right.$, 9]). This so-called urban heat island effect, though reported extensively in the literature, still is an ad hoc research topic since details of the mechanisms responsible for warm urban surface are still not clear. Specifically, the interactions between urban temperature and aerosol effects are only now being studied with greater detail.

Extreme high temperatures have been reported over many urban regions in the warm season. Meehl et al. [10] recently found that record high temperatures in the United States have outpaced record low temperatures over the period 2000-2009. Record-breaking high temperatures were reported from China and India in the summer 2009, causing hundreds of deaths (http://www.thaindian.com/newsportal/ enviornment/heat-wave-death-toll-rises-to-three-in-orissa 100185481.html). Sterl et al. [11] found that extreme temperatures would increase more rapidly than mean global temperatures in the future. Further, heat-wave events in urban areas caused significant loss of life in the Midwestern United States [12] and Europe [13, 14]. Cheval et al. [15] described Bucharest's urban heat island conditions during extreme heat conditions in 2007. They found evidence that the UHI could be enlarged or shifted under certain conditions. Zhou and Shepherd [8] found that the UHI between Atlanta and a surrounding rural station was larger during heat-waves. The research community must understand important physical processes related to the urban surface temperature in order to accurately simulate and predict it [16-19].

Aerosols affect the surface temperature mainly via two mechanisms. The first mechanism involves altering surface insolation through scattering and absorption by atmospheric aerosol layers (namely, the aerosol direct effect, [20]). In general, aerosols reduce surface insolation and consequently reduce surface temperature. Since sulphate aerosols typically 
are most abundant over urban regions, it is often argued that aerosols have a net cooling effect (it was reported that black carbon has significant absorption on shortwave and longwave radiation [21]. Nevertheless, sulphate aerosols strongly scatter solar radiation and thus reduce surface insolation) [21]. The second mechanism involves changing cloud properties through aerosol microphysical and radiative pathways (the so-called "indirect effect"), which in turn influences the surface energy balance. The latter (aerosolcloud-interaction), although widely studied, is still far from understood due to complex microphysical processes [2225]. Our paper focuses on the aerosol direct effect to assess how much urban surface temperatures are reduced by that mechanism.

Previous research by Jin et al. [4], among others, reported that urban aerosols over New York City reduce surface insolation by $20 \mathrm{Wm}^{-2}$. But that study only used one random day of aerosol observations in September, and then employed a radiative transfer model [26] to calculate the change in surface insolation induced by urban aerosol scattering. Two key remaining issues that we address herein are (1) how exactly is surface temperature, rather than the surface insolation, reduced in the urban system? (2) Is there any seasonal variation in surface insolation reduction since urban aerosol loading has seasonality? This paper aims to shed light on these two questions using both remotely sensed aerosol observations and a regional climate model.

Specifically, the approach of this study is to assess aerosol load and microphysical properties over Beijing, New York City, Mexico City and Moscow using ground observation sites of the National Aeronautics and Space Administration (NASA) AERONET (AErosol RObotic NETwork, [27]). Next, the aerosol properties are input into a radiative transfer model [26] to quantify reductions in surface insolation $(\delta S)$ as a function of urban aerosols. The final step is to calculate skin and 2-m air temperature reduction induced by $\delta \mathrm{S}$ through an atmosphereland surface model governed by the land surface energy balance.

Key parameters for determining the aerosol direct effect on surface insolation are the microphysical properties of aerosols, in particular, the single scattering albedo, the asymmetry factor, and aerosol amount in the atmospheric column. These parameters can be directly measured or retrieved from the AERONET ground-based sites. With these properties and certain assumptions, including that surface and vertical distributions of aerosol are uniform, the radiative transfer model can be used to calculate $\delta \mathrm{S}$. After determining $\delta S$, the temperature can be derived from surface insolation, surface properties, and soil moisture using the most recent version of the Weather Research and Forecasting (WRF) Model.

Urbanization is an extreme case of land cover change characterized by transformation of original vegetation-covered surface to impervious surfaces like water-proof roads, buildings, and parking lots. Such land cover change reduces soil moisture (Running et al. 2006), albedo and emissivity [9], and vegetation coverage, and consequently, alters various subcomponents of Earth systems, particularly the water, carbon, and nitrogen cycle [28].
Land cover is described by a land surface model using a set of thermal and dynamic parameters, following the firstgeneration land models circa 1980s [29]. The most critical parameters are albedo, leaf area index, vegetation fraction cover, thermal and moisture conductivity. Satellite-observed albedo, emissivity, and vegetation index, can be directly used in the land surface models to represent the urban system [17].

Two types of surface temperature measurements are examined in this study: $2-\mathrm{m}$ screen temperatures ( $T_{\text {air }}$ : surface air temperature at $2-\mathrm{m}$ reference level. This screen-level temperature is the thermodynamic temperature obtained by thermometers that are sheltered in water-permeable wooden boxes located at $1.5-2 \mathrm{~m}$ above flat grass. $T_{\text {air }}$ is conventionally used in climate studies to detect global temperature variations (Jones et al. 1999, Karl et al. 1993) and urban heat-waves) (i.e., $T_{\text {air }}$ ), and land surface skin temperature $\left(T_{\text {skin }}\right.$, land surface skin temperature, is the radiometric temperature derived from surface emission. This temperature is closely related to land surface radiative properties (Jin et al. 1997). The $T_{\text {skin }}$ data used herein are developed from MODIS infrared channels. See Section 2 Data Sets for details) $\left(T_{\text {skin }}\right)[4,9]$. Both temperatures are critical because $T_{\text {skin }}$ is directly related to the surface energy balance and $T_{\text {air }}$ is the traditional variable used in UHI studies [1]. More importantly, because $T_{\text {skin }}$ and $T_{\text {air }}$ have different physical meanings and responses to radiative forcing at different rates and magnitude (Jin and Dickinson 2002), we expect different responses of $T_{\text {skin }}$ and $T_{\text {air }}$ due to the aerosol direct effect. Examining urban $T_{\text {skin }}$ changes and mechanisms that govern the $T_{\text {skin }}$ changes is critical to realistically predicting the spatial-temporal variations of urban surface temperature.

This study focuses only on assessing the direct effect of aerosols on surface temperatures $\left(T_{\text {skin }}\right.$ and $\left.T_{\text {air }}\right)$. $T_{\text {skin }}$ changes can be connected not only to changes in greenhouse gases (we fully understand the critical role of greenhouse gases (GHG) in global warming. Since many others have been working on GHG effect, our project is designed to study how other facets such as aerosol change may contribute to surface warming) but also to changes in land use (i.e., urbanization, desertification, agricultural practice, etc.), cloud cover, rainfall patterns, or aerosols. It is essential to identify urban aerosol effect on $T_{\text {skin, }}$, which is relatively new in urban research. Section 2 discusses the data sets used in this study, followed by Results and Discussions (Section 3). Final discussion is given in Section 4.

\section{Data and Model}

2.1. Land Surface Skin Temperature. The Moderate Resolution Imaging Spectroradiometer (MODIS) instrument is carried on NASA's Terra satellite, launched in December 1999, and NASA's Aqua satellite, launched in May 2002. Skin temperatures were retrieved using 7 solar and 3 thermal spectral bands [30] at 10:30 LT and 22:30 LT daily (Terra) and 13:30 LT and 1:30 LT (Aqua). Each pixel has a $1 \mathrm{~km}$ resolution at nadir [31]. The measurements used in this study have been scaled up to a $5 \mathrm{~km}$ resolution and averaged 
to monthly values by the MODIS land team [32]. Since only skin temperature under clear skies can be measured, only the values with quality flags attesting to the absence of clouds are used.

2.2. AERONET Observations. Ground-based, continuous aerosol observations conducted by the NASA AErosol RObotic NETwork program are used. AERONET has sites over Beijing (site name Beijing, $39^{\circ} 58^{\prime} \mathrm{N}, 116^{\circ} 22^{\prime} \mathrm{E}$ ), New York City (site name CCNY, $40^{\circ} 49^{\prime} \mathrm{N}, 73^{\circ} 56^{\prime} \mathrm{W}$ ), Mexico City $\left(19^{\circ} 20^{\prime} \mathrm{N}, 99^{\circ} 10^{\prime} \mathrm{W}\right)$, and Moscow $\left(55^{\circ} 42^{\prime} \mathrm{N}, 37^{\circ} 30^{\prime} \mathrm{E}\right)$. Level 2 data, which are quality assured and include single scattering albedo, aerosol optical thickness, and the asymmetry factor are examined in the analysis of monthly local aerosol loading $[33,34]$. Two limits related to AERONET observations that must be acknowledged for this investigation and future studies are that AERONET sites can only measure aerosols under clear-sky condition, and for certain sites, the observation time is not long enough or the data quality is not as robust as other sites. For example, year 2005 data for New York City is of questionable quality and thus is removed from this analysis. Level 2 data is available for AOD and high single scattering albedo and refractive indices cases. There are only a few cases in March, April, and October in New York City (NYC) and very few cases in February, March, April, and October for Moscow in which measurements reveal such high AOD. Nevertheless, Level 2 data may still shed light on the relative pollution condition of a city.

2.2.1. Weather Research and Forecasting (WRF) Model Sensitivity Study. Governed by the land surface energy balance, urban surface temperature varies as a function of surface insolation, heat redistribution, soil moisture, wind speed, albedo, emissivity, and other factors. It is impossible to know exactly how surface temperature would change without considering the complex interactions among soil, vegetation, and atmosphere [29]. Therefore, a numerical simulation approach is appropriate to investigate the land surface temperature change following the surface insolation reduction $(\delta S)$ induced by the direct effect of urban aerosols.

In order to assess the surface responses to the aerosolinduced $\delta \mathrm{S}$, the Weather Research and Forecasting (WRF) model version 3 [35] is used in this study. WRF is a community-developed mesoscale weather prediction system which has demonstrated capability to simulate or predict mesoscale atmospheric circulation. We use a two-way interactive, nested-grid technique and the configuration consists of an $18-\mathrm{km}$ outer domain with horizontal grid spacing of $201 \times 200$ grid points, and a 6-km fine domain with a horizontal grid spacing of $154 \times 151$ grid points, at the center of domain of $40.0^{\circ} \mathrm{N}, 116.0^{\circ} \mathrm{E}$. A total of 27 full $\sigma$ levels in the vertical are used with the model top at $50 \mathrm{hPa}$. We also employ a stretched vertical grid to improve resolution near the surface. In this study, the primary model physics activated in WRF include the Rapid Radiative Transfer Model (RRTM) longwave radiation; Dudhia shortwave radiation; Yonsei University (YSU) planetary boundary layer scheme; WRF Single-Moment 3-Class (WSM) cloud microphysics;
Kain-Fritsch (new Eta) convective parameterization; MoninObukhov surface-layer scheme; and unified Noah landsurface model $[36,37]$. The urban canopy model (UCM, [38]) can represent the thermal and dynamical effects of urban regions but is not used due to the lack of urban morphological parameters for the study region. Instead, the urban effects are parameterized via the Noah land surface model. The digital elevation is attained using 30second United States Geological Survey (USGS) topography data. The USGS 24-category data set is used to represent surface characteristics in the model, and Category 1 denotes urban and builtup land. For Category 1, the albedo is 0.15 and momentum roughness length is $0.80 \mathrm{~m}$. Beijing city is located at $39^{\prime \prime} 56^{\prime} \mathrm{N}$ and $116^{\prime \prime} 20^{\prime} \mathrm{N}$. According to the recent distribution of building height data in Beijing, we assign the domain of $39.7-40.1^{\circ} \mathrm{N}$ and $116.1-116.7^{\circ} \mathrm{E}$ as the Beijing area in the model. The outermost coarse-mesh lateral boundary conditions are specified by linearly interpolating the National Centers for Environment Prediction (NCEP) 6-hourly Final Analyses (FNL) at a resolution of $1^{\circ} \times 1^{\circ}$ degree.

Two 48-hour simulations starting from 00Z July 26, 2008 to $00 \mathrm{Z}$ July 28,2008 were conducted as control and sensitivity runs, respectively. The sensitivity run differs from the control run only in the reduction of surface insolation of $100 \mathrm{Wm}^{-2}$ in daylight hours within the domain of $39.7-40.1^{\circ} \mathrm{N}$ and $116.1-116.7^{\circ} \mathrm{E}$. While this is a simplified experiment, it does provide insight on how the skin and 2-m air temperatures change. A sensitivity study over other periods of time has also been conducted (not shown), but the results presented herein are typical.

It should be noted that in this experiment reducing aerosol-induced surface insolation over urban region should not be interpreted to mean that aerosols have no such effect over nonurban region. In fact, aerosol effects on solar radiation exist wherever aerosols are present. Nevertheless, these numerical experiments are designed to simplify a complicated set of processes to examine the pertinent physical processes. The focus of this study is on how much urban aerosols reduce surface temperature over urban region, not aerosol effect on urban heat island effect (i.e., the difference in temperature between urban and surrounding regions).

\section{Results and Discussions}

3.1. Observed Urban Heat Island Effects. The urban region is shown in the land cover maps (Figures 1(c) and 1(d)) for Beijing and New York City, respectively. The Beijing region's (center $39^{\circ} 50^{\prime} \mathrm{N}, 116^{\circ} 40^{\prime} \mathrm{E}$ ) monthly skin temperatures in July 2008 are as high as $308-314 \mathrm{~K}$ (Figure 1(a)), while the exception is for arid and mountainous regions in the NW part of the region where the temperatures exceed $303 \mathrm{~K}$. Similarly, New York City (NYC) has a temperature range of 300-310 K (Figure 1(b)), while NYC's surrounding regions have skin temperatures near 298-304 K. These results are based on monthly averages from Terra (10:30 AM). At the instantaneous scale, the UHI signal could be much stronger than the average value [4]. Urban pixels can be identified using MODIS land cover data (see $[39,40])$. 


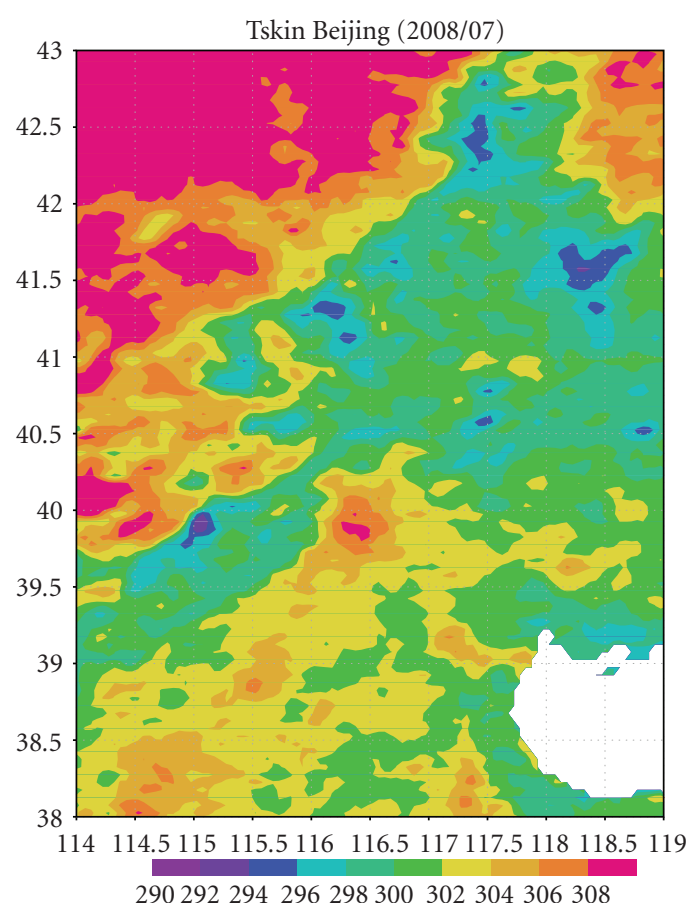

(a)

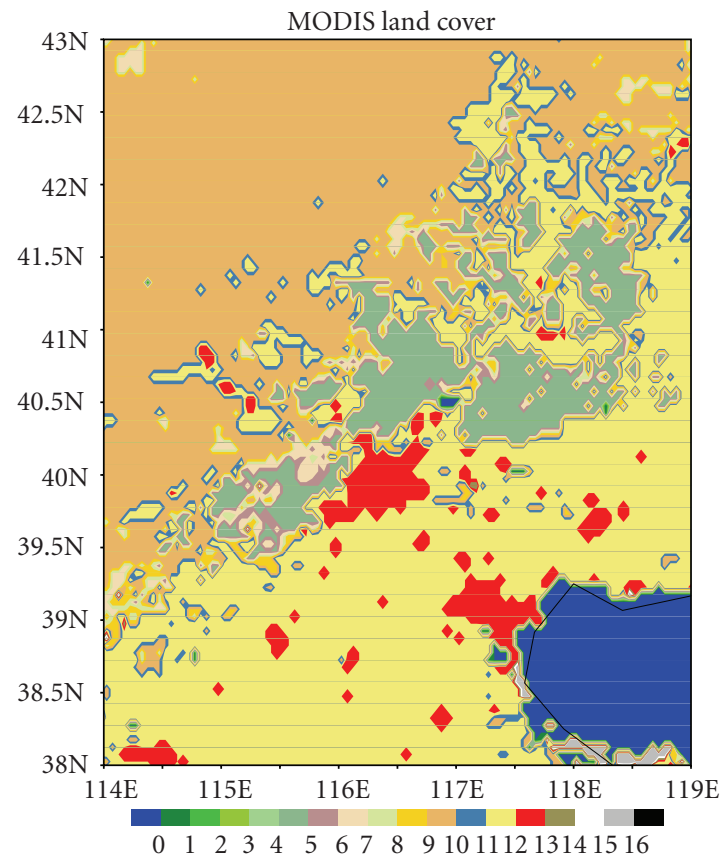

(c)

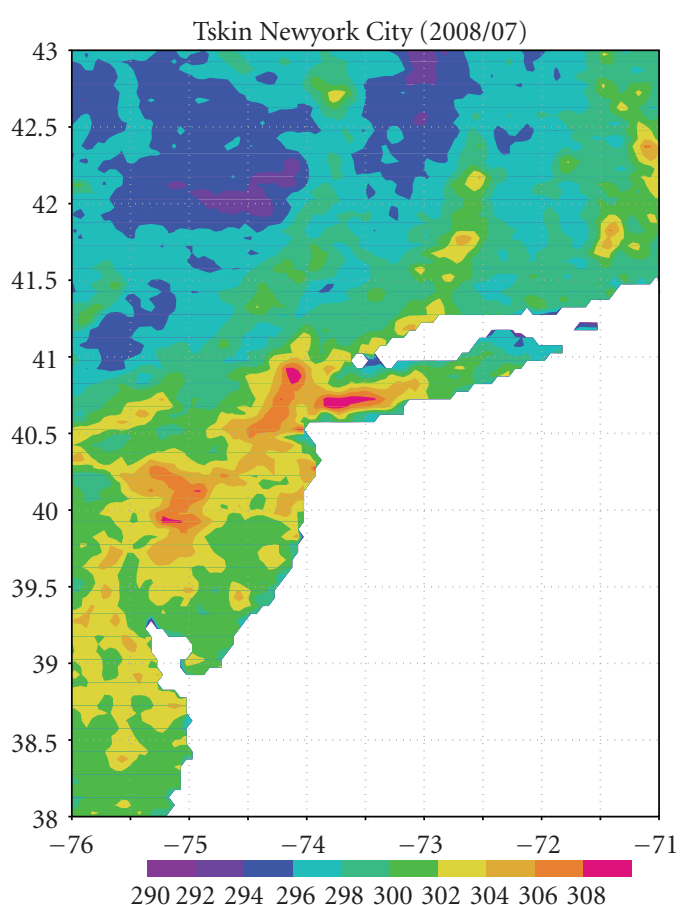

(b)

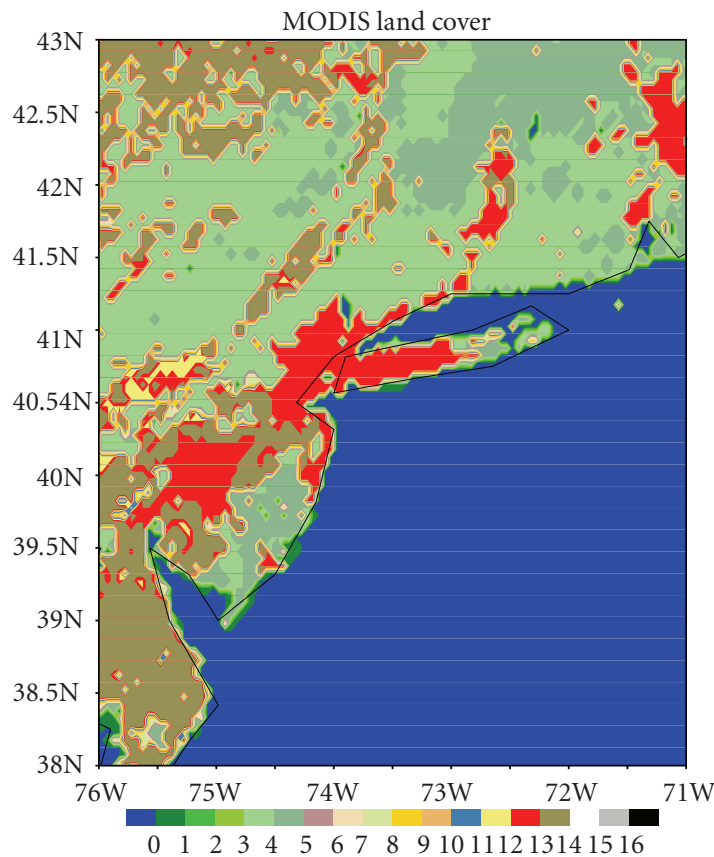

(d)

FIGURE 1: MODIS observed monthly mean land surface skin temperature starting from July 2000. (a) Beijing and (b) New York City (NYC). (c) is land cover map for Beijing region and (d) is land cover for New York City region. The land cover is defined by MODIS as (1) evergreen needleleaf forest, (2) evergreen broadleaf forest, (3) deciduous needleleaf forest, (4) deciduous broadleaf forest, (5) mixed forest, (6) closed shrubland, (7) open shrubland, (8) woody savannas, (9) savannas, (10) grassland, (11) permanent wetland, (12) cropland, (13) urban and builtup, (14) cropland/natural vegetation mosaic, (15) snow and ice, (16) barren or sparsely vegetated. In addition, 0 is water.

The advantage of the satellite observations is that there is one $T_{\text {skin }}$ observation for each pixel, therefore we can examine all urban pixels within an area to reveal its $T_{\text {skin }}$ relationship compared with surrounding nonurban regions. For example, the area-averaged, skin-level UHIs are observed at Beijing and NYC (Figure 2). For July 2008, within a $0.6^{\circ} \times 0.6^{\circ}$ box centered on Beijing (39.7-40.3 $\mathrm{N}, 116.1-$ $116.7^{\circ} \mathrm{E}$ ), the urban-pixel-averaged $T_{\text {skin }}$ is higher than otherland-cover-averaged $T_{\text {skin }}$ present in the 0.6 by 0.6 degree box. In this box, $60.4 \%$ of pixels are urban cover $(\mathrm{LC}=13)$, 


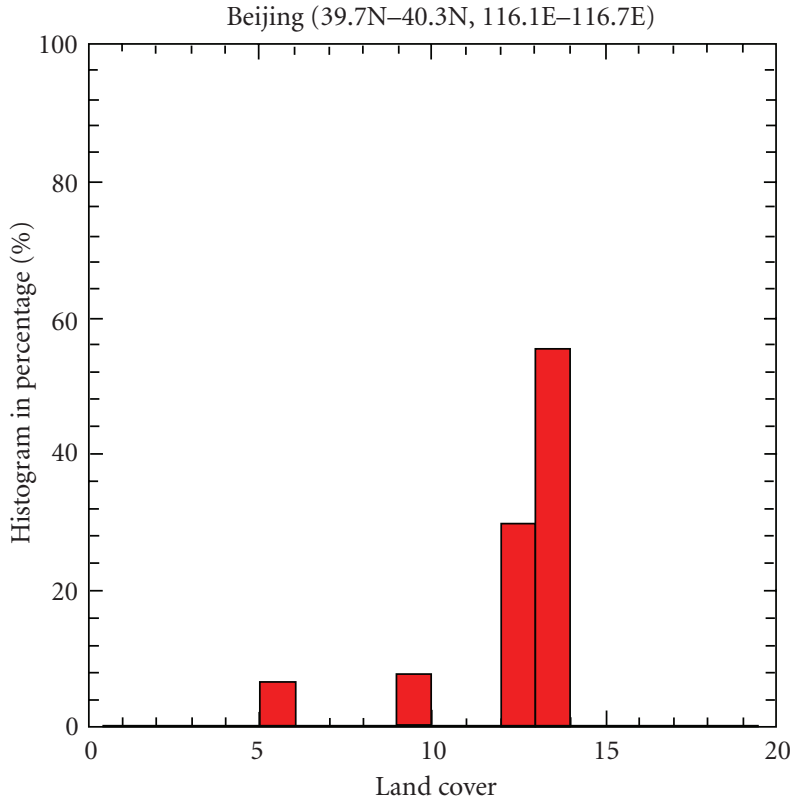

(a)

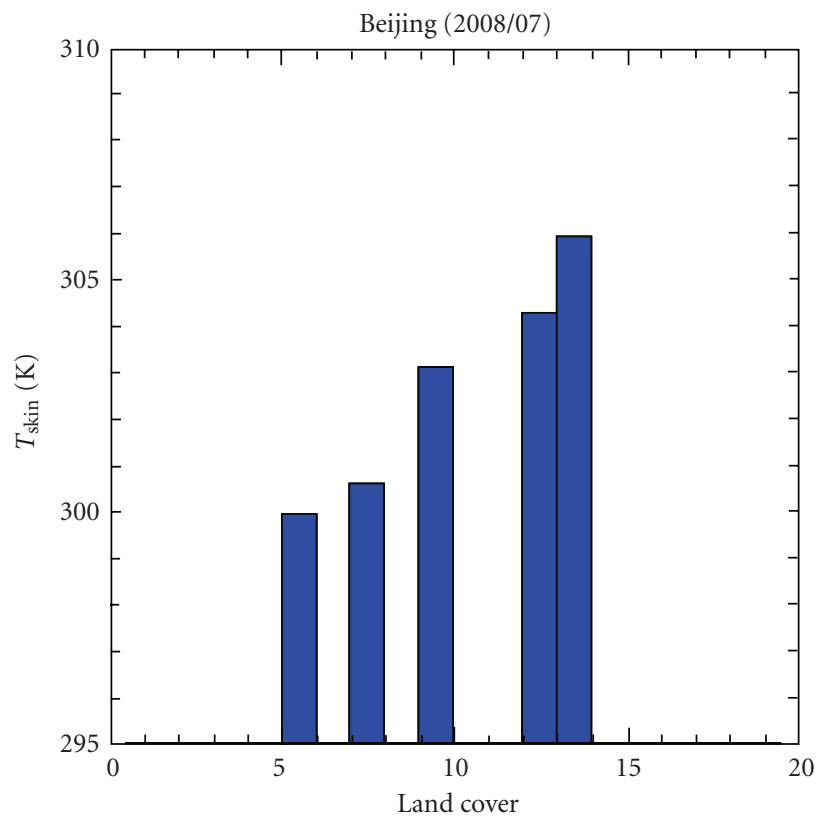

(c)

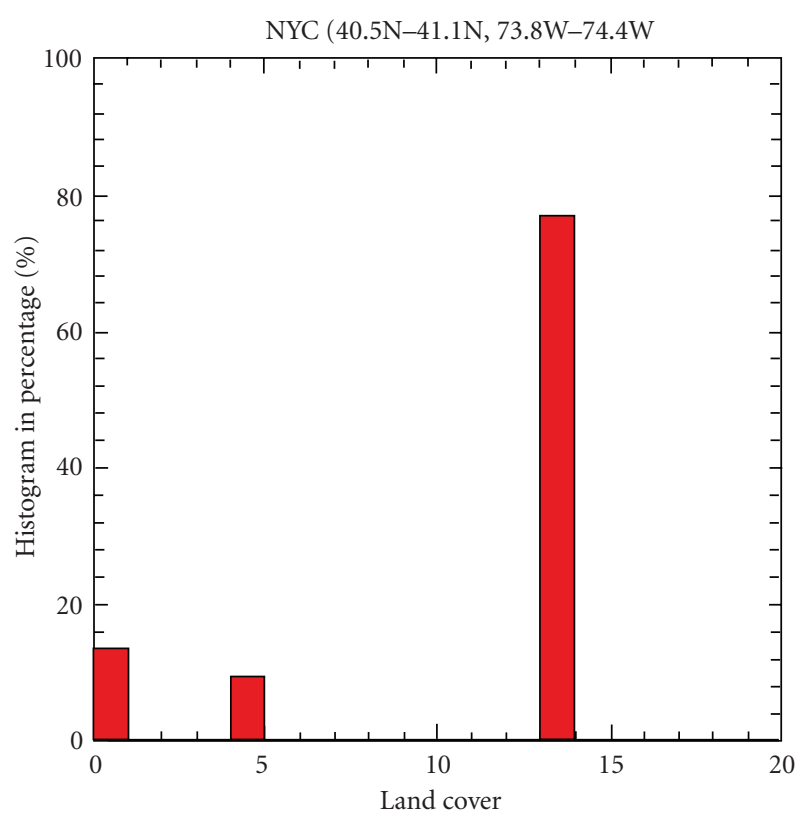

(b)

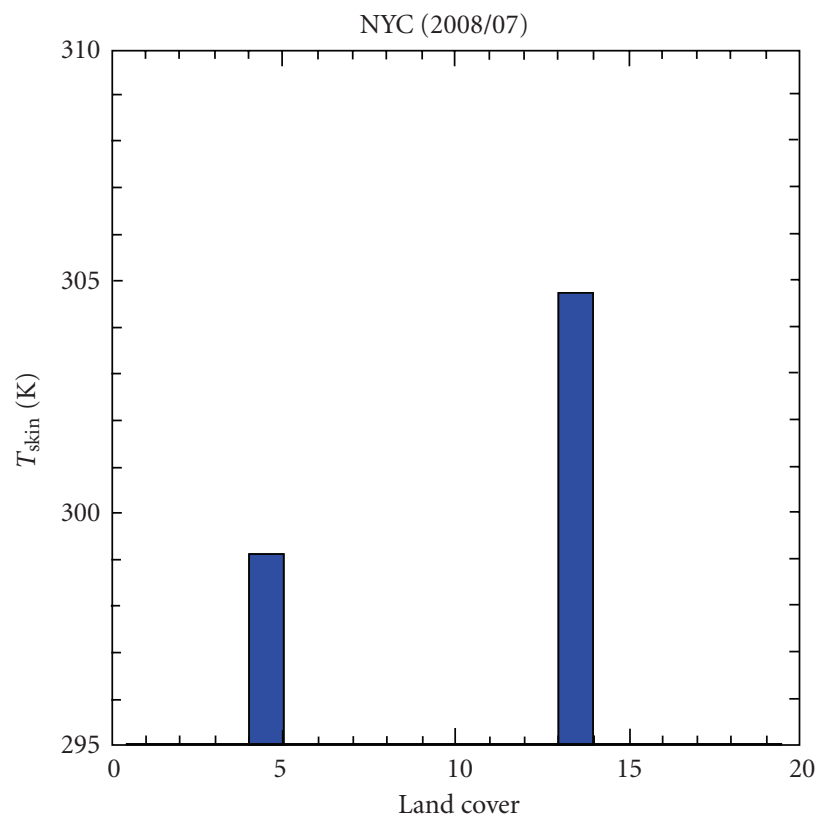

(d)

Figure 2: Land-cover averaged skin temperature for Beijing and New York City. (a) and (b) are land cover percentages for $0.6 \times 0.6$ box for Beijing $\left(39.7^{\circ}-40.3^{\circ} \mathrm{N}, 116.1^{\circ}-116.7^{\circ} \mathrm{E}\right)$ and New York City $\left(40.5^{\circ}-41.1^{\circ} \mathrm{N}, 78.3^{\circ}-74.4^{\circ} \mathrm{W}\right)$. Land cover type is defined in MODIS as $(1)$ evergreen needleleaf forest, (2) evergreen broadleaf forest, (3) deciduous needleleaf forest, (4) deciduous broadleaf forest, (5) mixed forest, (6) closed shrubland, (7) open shrubland, (8) woody savannas, (9) savannas, (10) grassland, (11) permanent wetland, (12) croplands, (13) urban and built-up, (14) cropland/natural vegetation mosaic, (15) snow and ice, (16) barren or sparsely vegetated. (c) and (d) are skin temperature versus land cover in the $0.6^{\circ} \times 0.6^{\circ}$ boxes for beijing and new york city, respectively.

approximately $32.1 \%$ are cropland ( $\mathrm{LC}=12), 8.2 \%$ are Savannas $(\mathrm{LC}=9)$, and $7.3 \%$ are mixed forest. Correspondingly, $T_{\text {skin }}$ values include all-urban-pixel-averaged Beijing area $(306 \mathrm{~K})$, cropland (304 K), Savanna (303 K), and mixed forest $(300 \mathrm{~K})$. Other land covers near the Beijing area are too small to be apparent in the land cover figure (Figure 2(a)). However, their $T_{\text {skin }}$ values are all lower than urban $T_{\text {skin }}$.
Similarly, a 0.6 by 0.6 degree box is selected over the NYC area $\left(40.5-41.1^{\circ} \mathrm{N}, 73.8-74.4^{\circ} \mathrm{W}\right)$. Over this box, $78 \%$ of pixels are urban $(\mathrm{LC}=13)$, and $T_{\text {skin }}$ is $304.8 \mathrm{~K}$, while $15.4 \%$ are water $(\mathrm{LC}=0)$ (no $T_{\text {skin }}$ is presented since this specific research only studies land cover $\left.T_{\text {skin }}\right)$ and $12.2 \%$ are mixed forest $(\mathrm{LC}=5)$ with $T_{\text {skin }}$ of $299.2 \mathrm{~K}$. The UHI is evident in the satellite $T_{\text {skin }}$ field. It is also apparent that 


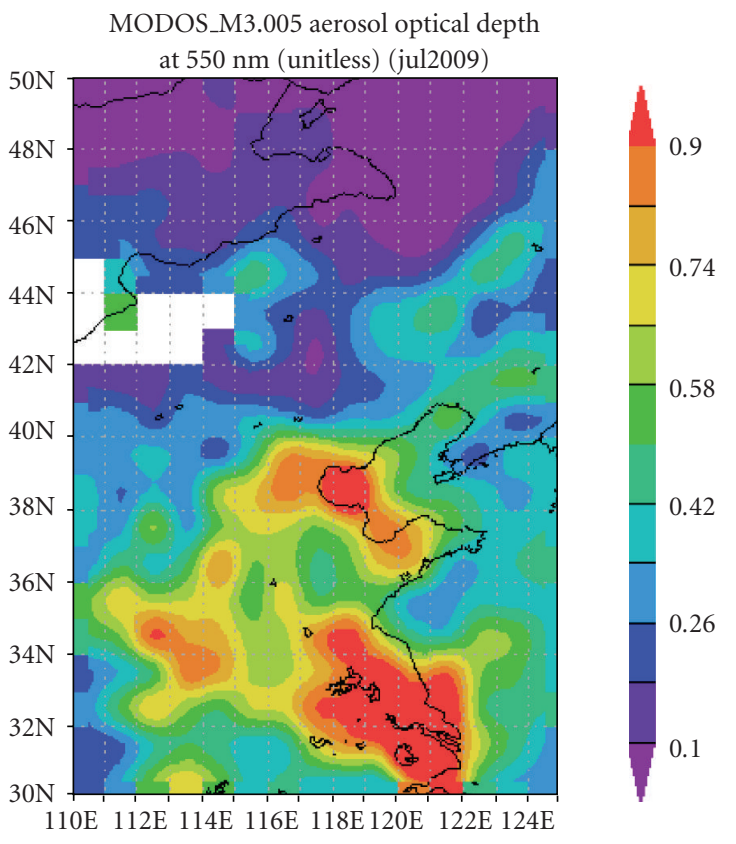

Figure 3: Monthly aerosol optical thickness for August 2008. Observation is from MODIS Terra daytime pass (10:30 AM) via 0.55 micrometer. The image is plotted via http://gdatal.sci.gsfc. nasa.gov/daac-bin/G3/gui.cgi?instance_id=neespi.

a skin temperature UHI is observed during the daytime. Traditionally, the air temperature UHI is maximized at night or in the very early morning hours [5]. We will say more on this in later sections. For comparison, relatively larger boxes are selected and the same UHI signal is observed, namely, urban $T_{\text {skin }}$ is higher than those over other land covers.

3.2. Observed Urban Aerosols. Figure 3 shows the spatial distribution of aerosol optical thickness, a parameter indicating aerosol loading within the total atmospheric column. The Beijing region has heavy aerosols due to urban construction, traffic, and air conditioning. In the nearby nonurban regions, aerosol load is generally less. If nonurban regions have relatively less aerosols, the aerosol direct effect on $T_{\text {skin }}$ would not be as significant as that over urban regions. Nevertheless, since MODIS aerosol data have coarse resolution and problems with the land surface in the retrievals [41], we have to be cautious when applying MODIS data to assess urban and nonurban aerosol concentration.

Based on aerosol optical thickness, we divide the cities into two types: (a) heavily polluted and (b) normally polluted. Although the threshold to distinguish one from another is still a research topic, Beijing is considered heavily polluted because of its much higher aerosol concentration compared to NYC, Mexico City, and Moscow. This is revealed in the aerosol optical thickness parameters (AOT, Figure 4(a)) that were observed from AERONET. Urban aerosols are defined herein as aerosols over local urban regions including those transported from remote regions as well as produced by urban regions. Beijing's AOT at wavelength of $0.675 \mu \mathrm{m}$ peaks during the summer months with a maximum value of 0.8 . For comparison, the NYC AOT peaks in July at 0.2 while Moscow's value peaks in September at 0.18 . Mexico City has a bimodal peak in May and September around 0.22. The Beijing urban aerosol amount is significantly higher than other cities, and thus we selected Beijing as the focus of our research in the next three steps. In addition, the Beijing and NYC distributions exhibit seasonality, with maxima in summer and minima in winter. Moscow is less sensitive to seasonality. Moscow has peaks, which may be related to biomass burning and harvesting of agricultural crops. More importantly, Beijing has a higher annual AOT range than NYC and other cities. The seasonal range of NYC is only 0.15 (minimum is 0.05 in January and maximum is 0.2 in July) while the Beijing minimum (maximum) is in December (June) at $0.32(0.8)$. These measurements indicate that Beijing is more polluted than NYC and other cities; therefore it is reasonable to use Beijing as an extreme urban case to demonstrate how urban aerosols affect surface insolation and temperature.

The AERONET aerosol single scattering albedo plot of monthly means shows some unexpected features. Since AERONET Level 2 single scattering albedo (SSA) retrievals are only made for moderate-to-high $\operatorname{AOD}(\operatorname{AOD}(440 \mathrm{~nm})>$ $0.4)$, there are very few cases for March, April and October in NYC and very few in Feb, Mar, Apr, and Oct in Moscow. These are not robust samples for these months and therefore should not be implied as representative. Removing SSA data for months with less than 10-15 days of observations is suggested by AERONET investigators, although it seems unlikely that there would be more than 10 different days with SSA retrievals in March for NYC.

The single scattering albedo is the ratio of scattering to extinction, and it approaches unity for purely scattering particles, decreasing as the degree of absorption increases (increasing concentrations of carbon soot or absorbing minerals like hematite). In most months of the year (MayDecember), Beijing has a higher single scattering albedo than NYC, Moscow, and Mexico City (Figure 4(b)). For Beijing, the single scattering albedo ranges from 0.87 to 0.94 , with low values in winter and high values in summer. Although a few months of data are missing, both Moscow and Mexico City also exhibit seasonality in single scattering albedo with high values in summer and low values in winter. The seasonality of NYC's single scattering albedo, however, is not evident. Further research is required to determine why NYC has different features in aerosol single scattering albedo. Additionally, the high values for NYC in March are questionable.

Smaller asymmetry factors (Figure 4(c)) are related to smaller aerosol particles. Asymmetry factor is defined as the cosine weighting of the phase function and is a measure of how forward the scattering is. A zero is symmetric between forward and backscattering, such as Rayleigh scattering or isotropic scattering, in which the probability is just as great that the scattering is in the forward hemisphere as in the backscattering hemisphere. A value of 1 denotes complete forward scattering and -1 denotes complete backscattering in the $180^{\circ}$ direction. Aerosol particles typically have values 


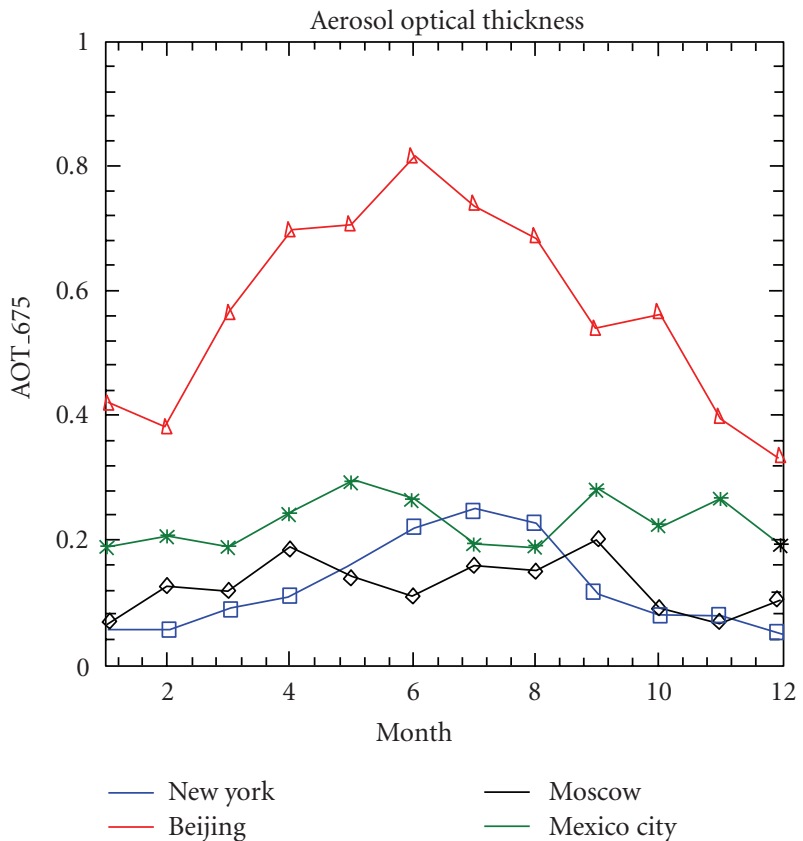

(a)

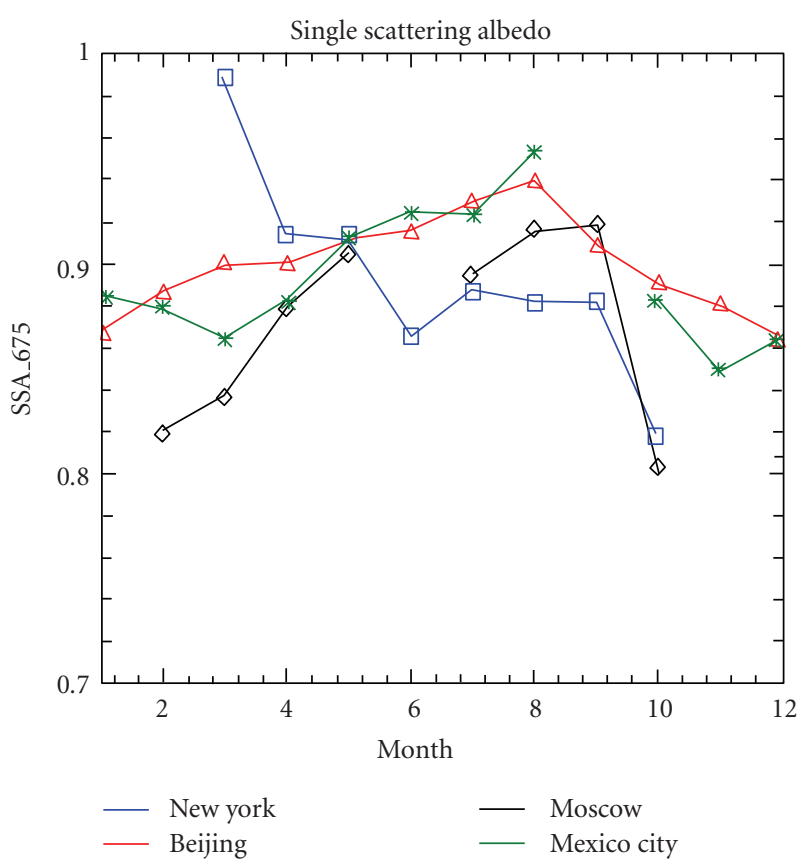

(b)

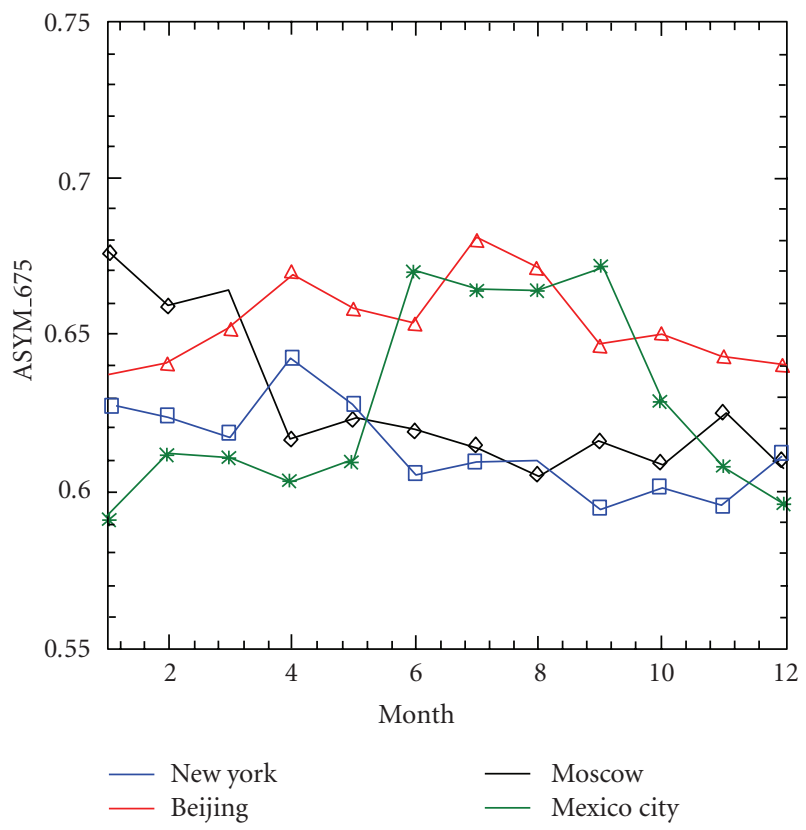

(c)

FIgURE 4: Monthly observations for (a) aerosol optical thickness, (b) single scattering albedo, and (c) the asymmetry factor from NASA AERONET sites for four cities (Beijing, New York City, Mexico City, and Moscow). Data are sampled from multiyear averages.

in the 0.7 range and cloud drops that are larger, compared to the wavelength, are more typically 0.85 . Together with AOT and single scattering albedo, this parameter is useful for obtaining the basic radiative properties of aerosols. In the summer, Beijing and Mexico City have higher asymmetry factors than NYC and Moscow, which means that aerosol particles over Beijing and Mexico City are larger than those over NYC.
3.3. Aerosol Reduction on Surface Insolation. Since Beijing represents an extremely-polluted city and New York City represents a normally polluted city, this section focuses on how the surface insolation changes in these two cities as a result of aerosol loads. We do not discuss rural aerosols here because of the unavailability of the observations. However, this should not be interpreted as suggesting that rural regions have no aerosols and aerosol effect. 


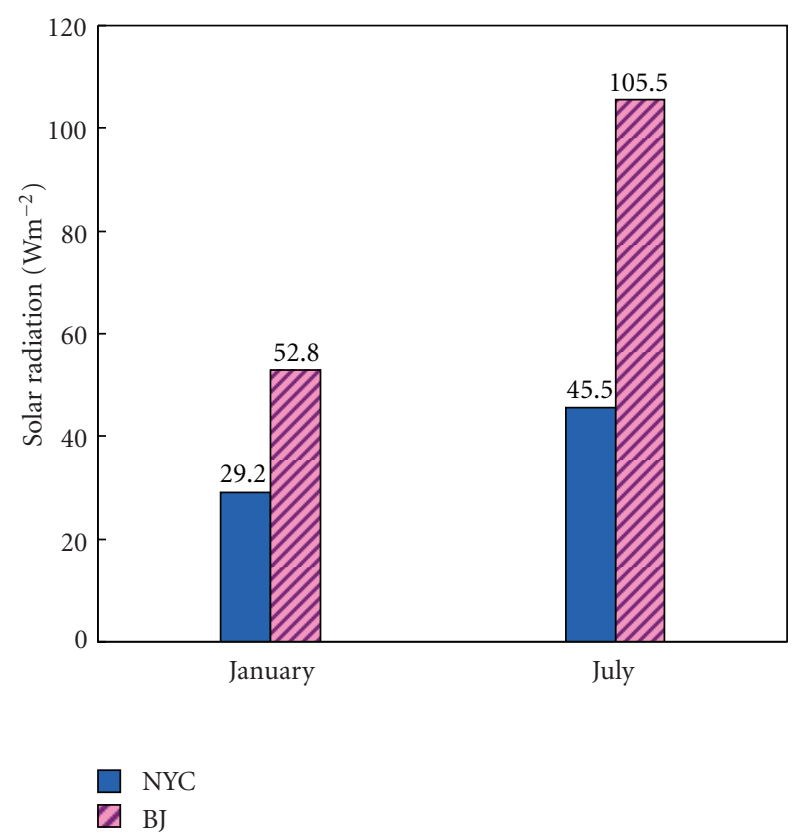

Figure 5: Aerosol reduction on surface insolation calculated from the radiative transfer model for Beijing and New York City in January and July, respectively.

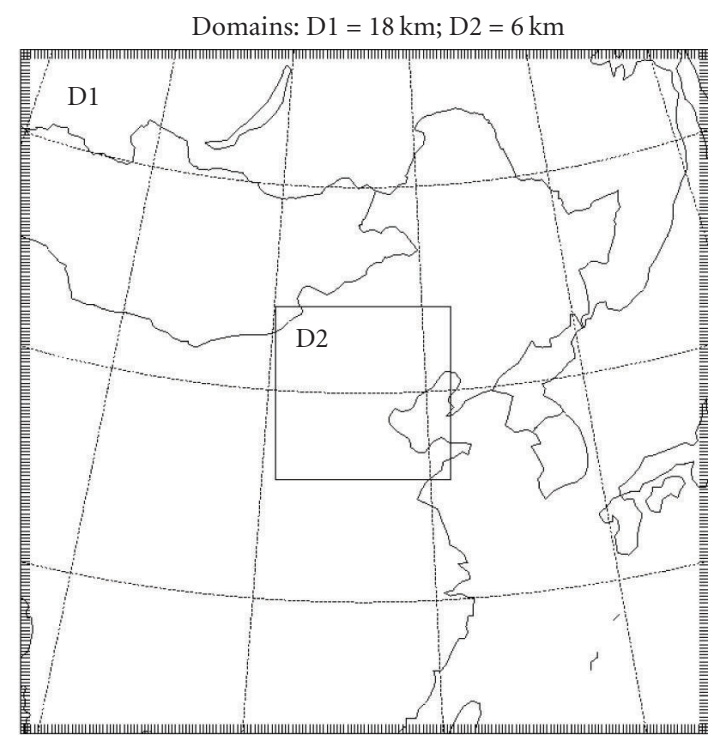

FIgURE 6: The domain size and location of the study. D1 resolution is $18 \mathrm{~km}$ and D2 resolution is $6 \mathrm{~km}$.

A radiative transfer model $[26,42]$ is used to simulate urban aerosol-induced changes in surface insolation based on the AERONET-observed aerosol optical properties for both Beijing and NYC (Figure 5). Top quartile, 6-year, instantaneous-averaged AOT, single scattering albedo, and asymmetry factor observed from NASA AERONET were input into the radiative transfer model to calculate how much surface insolation is reduced due to the direct effect. The vertical distribution of aerosols near the surface is assumed to be uniform. The vertical distribution of aerosols has a relatively minor effect on reduction of solar radiation at the surface. The sky is cloudy-free. In addition, the atmospheric conditions and surface albedo were predefined in the radiative transfer model to represent the surface [26]. The reduction of surface insolation $(\delta S)$ is a function of solar zenith angle as well as aerosol amount, and therefore, varies with seasons. The reduction of surface insolation $(\delta S)$ for NYC is less significant than in Beijing due to moderate AOT in this city (Figure 3). Specifically, for NYC, $\delta S$ is as low as $20 \mathrm{Wm}^{-2}$ in winter and as high as $40 \mathrm{Wm}^{-2}$ in summer. By more strongly scattering and absorbing solar radiation, the aerosols reduce surface insolation by about $105.5 \mathrm{Wm}^{-2}$ for Beijing during the summer and $50.5 \mathrm{Wm}^{-2}$ during the winter (January).

The $\delta S$ depends on atmospheric conditions of clouds and aerosols. Using different radiative transfer models or assumptions may result in slightly different values of $\delta \mathrm{S}$. The Chou and Suarez radiative transfer model [26] was employed because WRF's aerosol scheme is under development with unknown capability (Qian, personal communication 2009), and because Chou and Suarez' [26]) model has been adapted to calculate aerosols in various studies $[4,9,42]$.

3.4. Aerosol Reduction on Surface Skin Temperature $\left(T_{\text {skin }}\right)$ Model Simulations. Surface skin temperature $\left(T_{\text {skin }}\right)$ is a diagnostic variable in the land surface model of WRF. WRFNOAH, similar to most land surface models developed since the middle 1980s [29], simulates energy redistribution within the land surface-biosphere system in terms of upward longwave radiation, sensible heat flux, latent heat flux and ground heat flux. $T_{\text {skin }}$, one of the key variables that determines sensible and latent heat flux via the differences between the skin layer and air surface layer, is determined by both surface insolation as well as surface-biosphere conditions. The sensitivity simulations are conducted over the domain in Figure 6 for 27 July 2008, where Beijing is in domain 2 (D2). On this day, AERONET-observed AOD is 1.66 at $0.675 \mathrm{~nm}$, which is very high. Domain 1 (Figure 6) shows the area over which the WRF model conducts the overall regional sensitivity simulations. Domain 2 is at $6 \mathrm{~km}$ resolution representing the dense Beijing urban regions where surface insolation reduction $(\delta S)$ is reduced by $100 \mathrm{Wm}^{-2}$. Therefore, $T_{\text {skin }}$ is expected to decrease via the reduction of surface insolation. Nevertheless, our goal is to assess how much $T_{\text {skin }}$ is affected by aerosols and whether $T_{\text {skin }}$ responds to the aerosol direct effect in the same manner as $T_{\text {air }}$, in terms of magnitude and diurnal change.

Although the sensitivity study studies urban region, it should not imply that aerosols have no effect on rural regions. In fact, as long as aerosols are present, it would change solar radiation as function of aerosol properties in that region. In this paper, urban surface temperature change is our interest and thus we design our numerical experiments over urban regions.

The surface response to aerosol loading is largely determined by the surface and atmosphere conditions [23]. Therefore, Figure 7 presents the land conditions for the runs. Specifically, the soil category for Beijing is set (Figure 7(a)) to sand clay loam. Terrain height (Figure $7(\mathrm{~b})$ ) shows that 


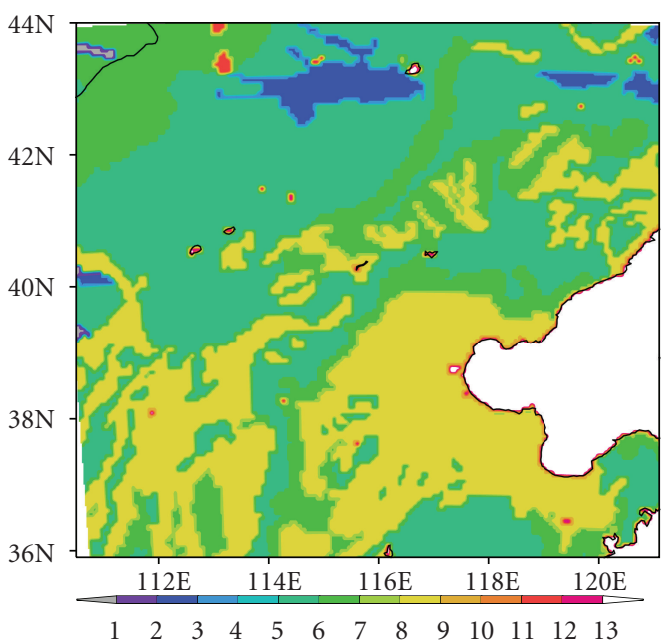

(a)

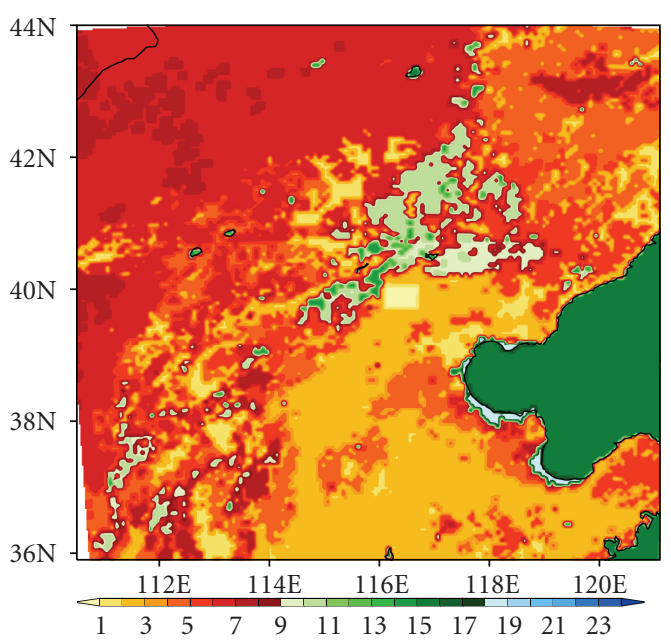

(c)

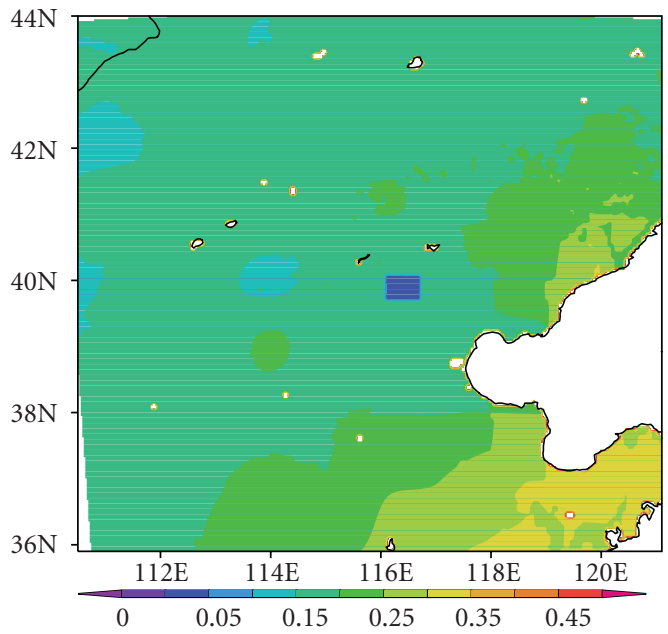

(e)

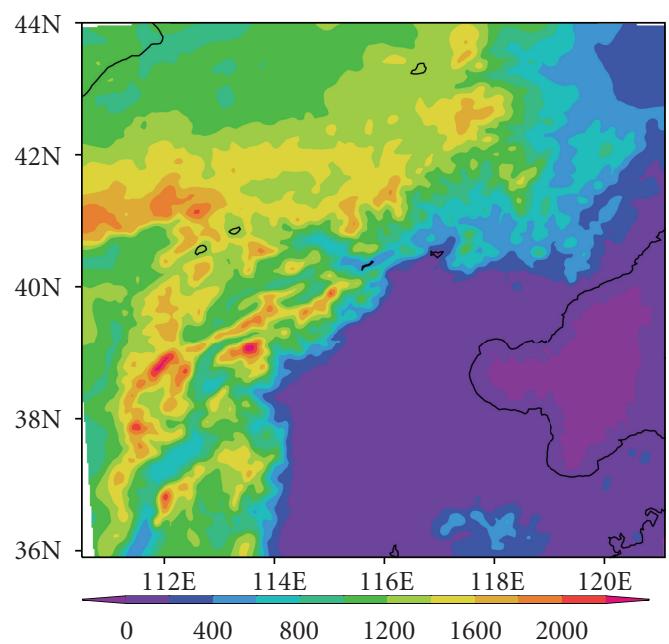

(b)

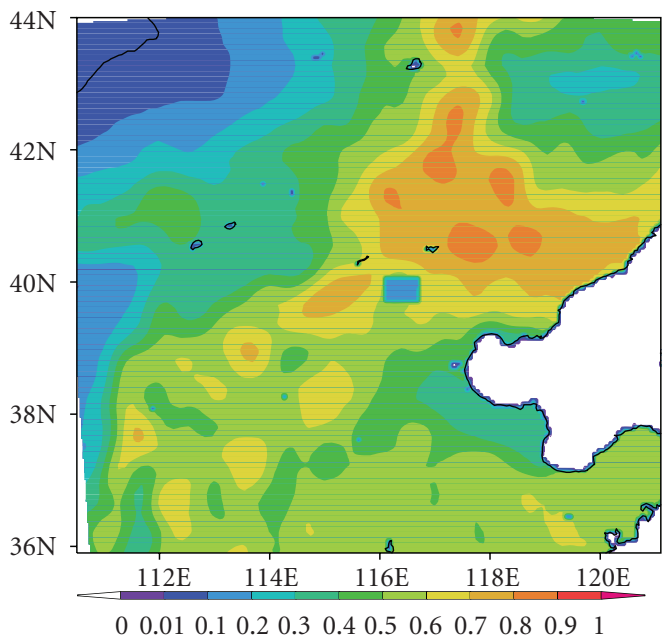

(d)

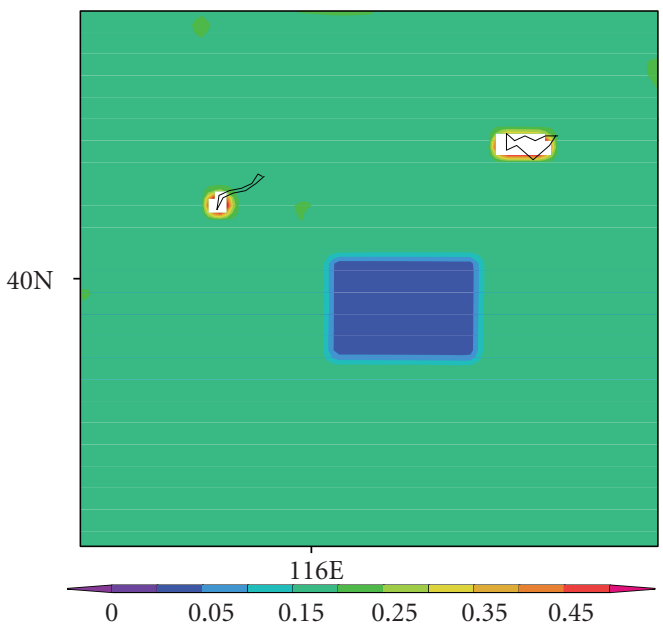

(f)

FIGURE 7: The land surface properties of the study domain in WRF: (a) soil category, (b) terrain height, (c) land use category, (d) green vegetation fraction $(\mathrm{GVF})$, (e) soil moisture at the first soil layer $(5 \mathrm{~cm})$ for domain 2 , and (f) the same as (e) but for analysis area. 


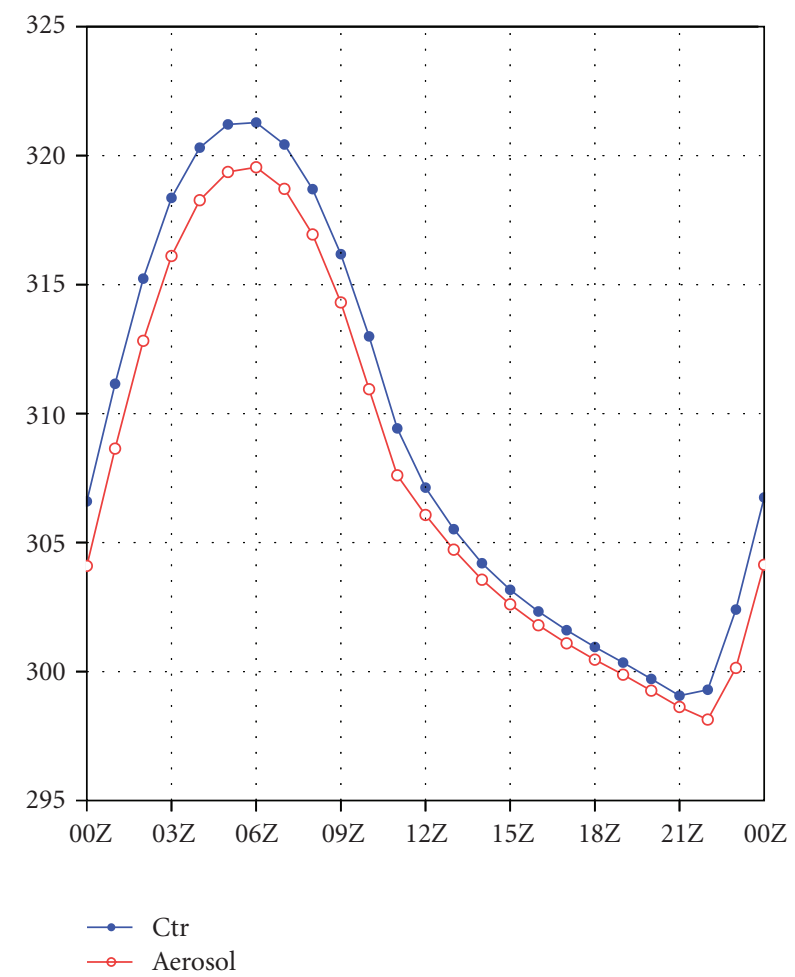

(a)

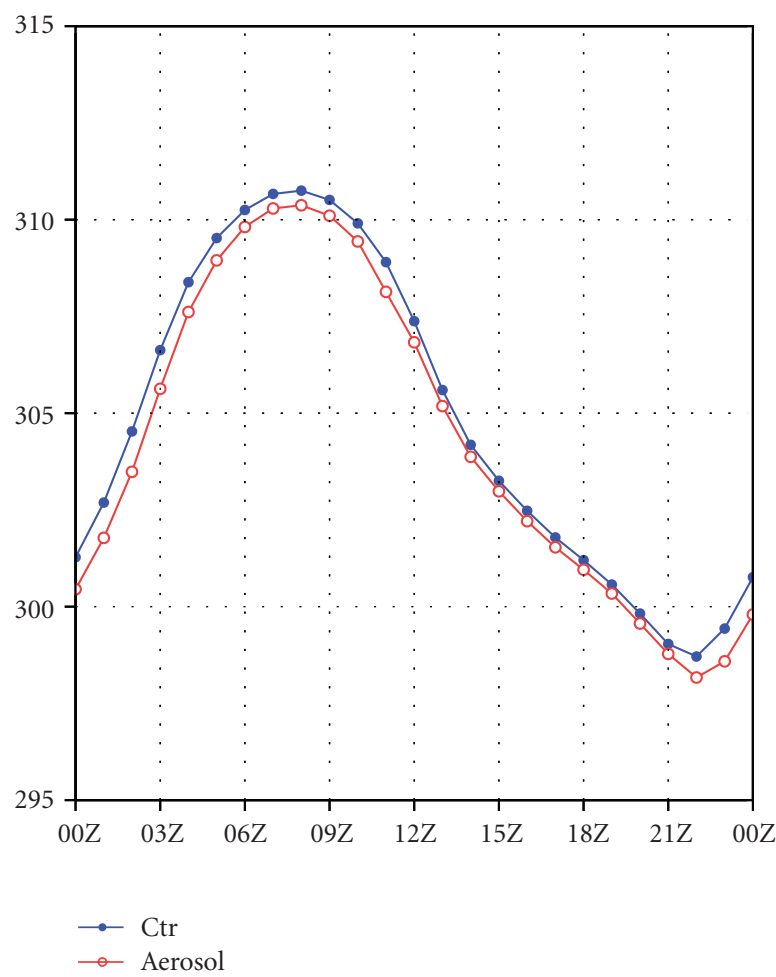

(b)

Figure 8: Aerosol effects on (a) land surface skin temperature, and (b) land surface $2 \mathrm{~m}$ air temperature. Model output for July $27,2008$. Averaged over Beijing $\left(39.7-40.1^{\circ} \mathrm{N}, 116.1-116.7^{\circ} \mathrm{E}\right)$.

Beijing is less than $200 \mathrm{~m}$ with much higher values in Northwestern surrounding regions and lower values in Southeastern regions. The land use in Beijing is categorized in the USGS 24-category as "urban and builtup land-1" (Figure 7(c)). Green vegetation fraction (Figure 7(d)) in Beijing is about 0.5 from the NCEP reanalysis data, which is obviously too high. Thus, in our runs we set this value as 0.2 as previous model development suggested [18]. Soil moisture in the first model soil layer in Beijing is $0.2-0.3 \mathrm{~m}^{3} \cdot \mathrm{m}^{-3}$, but we reset it as a smaller value (Figures $7(\mathrm{e})$ and $7(\mathrm{f})$ ).

The magnitude of $T_{\text {skin }}$ reduction (Figure 8(a)), up to $2.1^{\circ} \mathrm{C}$, is greatest during the period 6-9 AM (LST) for 27 July 2008. Such reduction occurs during the entire day, but the minimum is around 5-7 PM (LST). It should be noted that the only difference between these two runs (control versus sensitivity run) is $\delta S$ during daylight hours. Clearly, the aerosol direct effect propagates into the nocturnal hours because of the memory of land surface to energy changes in the daytime. By comparison, $T_{\text {air }}$ at $2 \mathrm{~m}$ (Figure $8(\mathrm{~b})$ ) shows a reduction due to the daytime aerosol direct effect. Nevertheless, the overall $T_{\text {air }}$ reduction is smaller than $T_{\text {skin }}$. For example, the maximum $T_{\text {air }}$ reduction is only $0.9^{\circ} \mathrm{C}$ at 9 $\mathrm{AM}$ and minimum reduction is only $0.45^{\circ} \mathrm{C}$ at $1 \mathrm{PM}$.

Figure 9 shows the spatial distribution of the $T_{\text {skin }}$ (Figure 9(a)), $T_{\text {air }}$ (Figure 9(b)) and $\delta T_{\text {skin }}$ and $\delta T_{\text {air }}$ (the sensitivity run minus the control run) at $12 \mathrm{Z} 27$ July 2008 , respectively (Figures 9(c) and 9(d)). $T_{\text {skin }}$ (Figure 9(c)) changes more than $T_{\text {air }}$ (Figure $9(\mathrm{~d})$ ) at this time. For comparison, the spatial distribution of $T_{\text {skin }}$ and $T_{\text {air }}$ reveals the heat gradient over the simulated regions. Corresponding to height (Figure 9(b)), the high mountains regions have low $T_{\text {skin }}$ and $T_{\text {air }}$, only the middle Beijing and southern region have higher temperatures. This geographical distribution also affects the surface temperature reduction due to the aerosol direct effect.

Figure 10 shows the $\delta T_{\text {skin }}$ and $\delta T_{\text {air }}$ at $18 \mathrm{Z} 27$ July 2008 . Clearly, at midnight, the aerosol effect on $T_{\text {air }}$ (Figure 10(b)) is now no longer noticeable. Namely, $\delta T_{\text {air }}$ is 0 for Beijing regions. On the contrary, $\delta T_{\text {skin }}$ is still evident, but the magnitude is only about $0.5-1{ }^{\circ} \mathrm{C}$. This may imply that $T_{\text {air }}$ has a shorter memory than $T_{\text {skin }}$ to the aerosol direct effect.

3.4.1. Sensitivity Studies with Albedo and Soil Moisture. Further sensitivity experiments were designed to examine the albedo effect on surface temperature. In the albedo experiment, albedo is designated as 0.15 and 0.10 , respectively. $T_{\text {skin }}$ values were compared from 00Z 27 July 2008 to $00 \mathrm{Z} 28$ July 2008. Figure 11 illustrates that with lower albedo (alb = $0.10), T_{\text {skin }}$ is always higher than in the high albedo case (alb $=0.15$ ). The largest differences, with $1.7 \mathrm{~K}$ peak difference, occur at 06Z 27 July 2008, which corresponds to local noon. Although the albedo effect is low during the night because of lack of insolation, $T_{\text {skin }}$ of the low albedo case is still higher than that of the high albedo case. This means that heat accumulated during the daytime can propagate to change the nighttime surface temperature. 


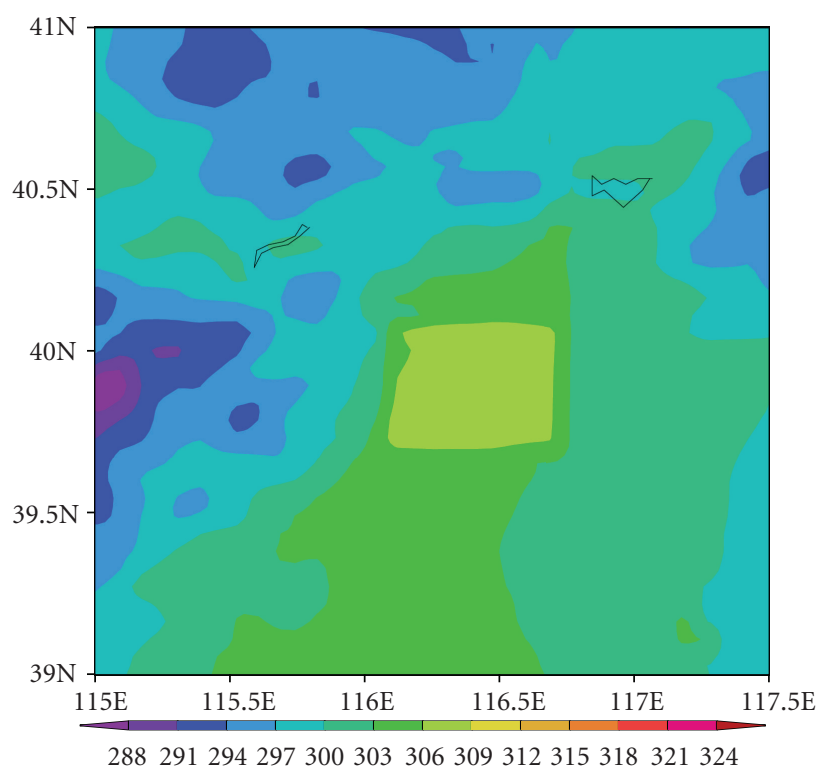

(a)

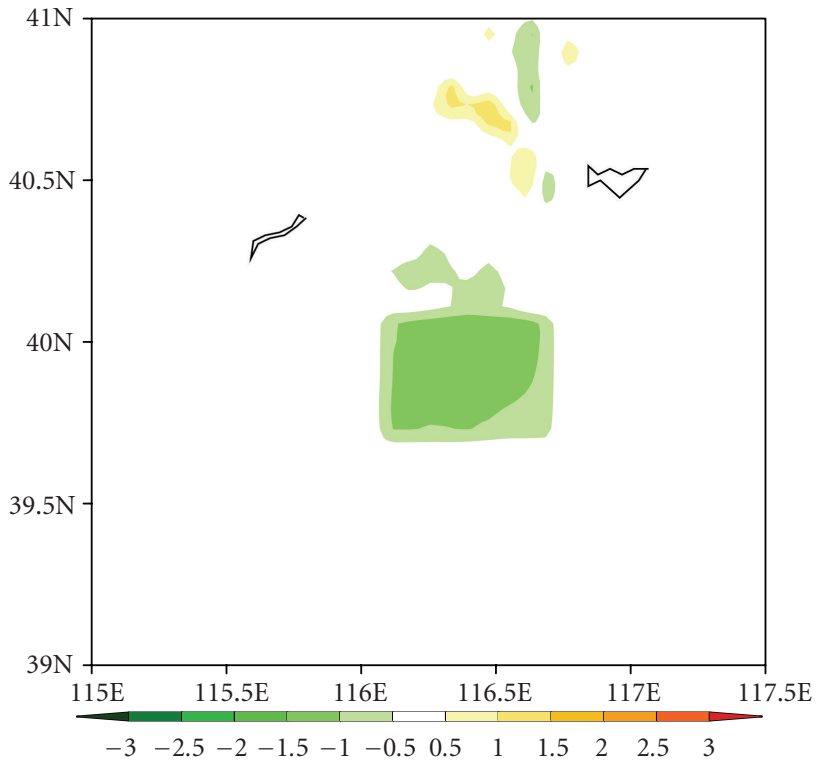

(c)

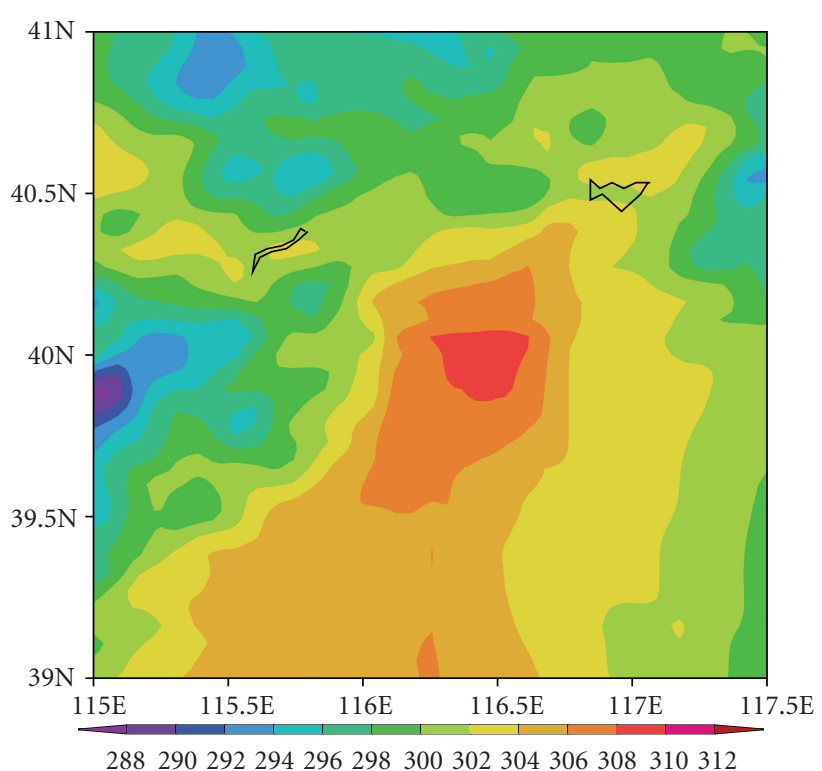

(b)

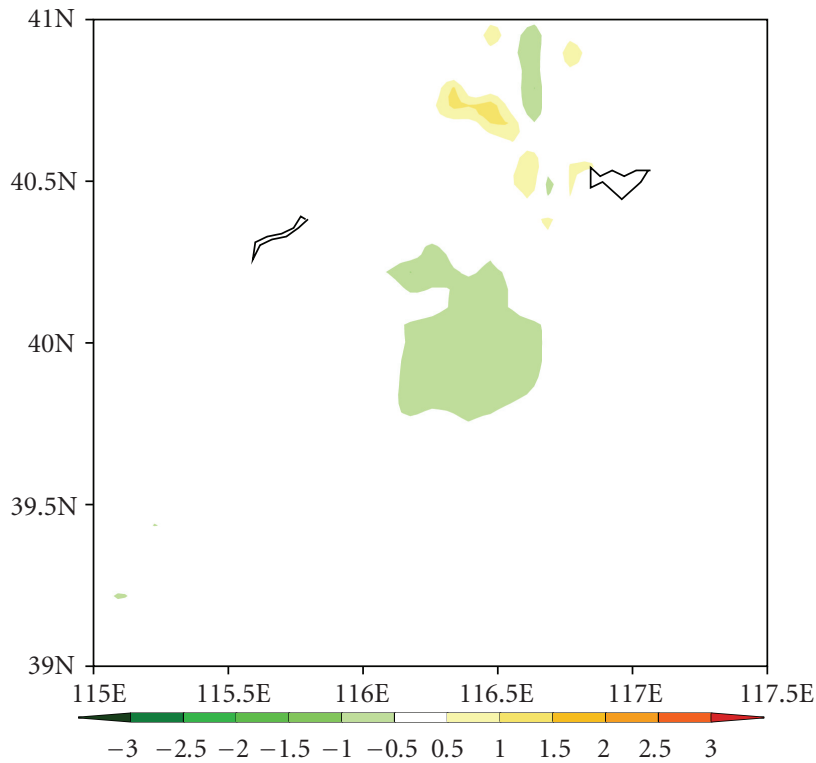

(d)

FIGURE 9: (a) the model output for the control run on skin temperature, (b) Model output for $2 \mathrm{~m}$ surface air temperature, (c) sensitivity run minus control run on skin temperature, and (d) sensitivity run minus control run on $2 \mathrm{~m}$ surface air temperature. The outputs are on 12Z, July 27, 2008.

Another sensitivity experiment is designed to examine the model's soil moisture effect on $T_{\text {skin. }}$. The Control run sets soil moisture as $0.15 \mathrm{~m}^{3} / \mathrm{m}^{3}$ interpolated from the NCEP reanalysis, and the sensitivity run sets the soil moisture as 0.001 (i.e., dry case). Figure 12 clearly reveals that with less soil moisture, the surface is warmer by $1.6 \mathrm{~K}$ during the daytime. This is because with less soil moisture, more of the absorbed surface insolation is redistributed to sensible heat flux and ground heat flux to warm the surface and underlying soil. Nevertheless, at night, the less-soil moisture case shows that the surface is cooler. This is mainly due to the stronger longwave radiative cooling of the dryer surface.

\section{Discussion}

Urban aerosols reduce both $T_{\text {skin }}$ and $T_{\text {air }}(2-\mathrm{m})$. This is a potential competing mechanism with land cover change for the urban warm surface. Namely, although significant changes in vegetation, land cover, and soil moisture over urban regions lead to a warmer surface, aerosols may offset such heating, partly, by reducing surface insolation. Nevertheless, the magnitude of aerosol-induced surface cooling is only $0.5-2^{\circ} \mathrm{C}$, and thus cannot fully offset the urban heat island effect, which is about $2-10^{\circ} \mathrm{C}$ warmer than surrounding regions in summer. It is important to note 


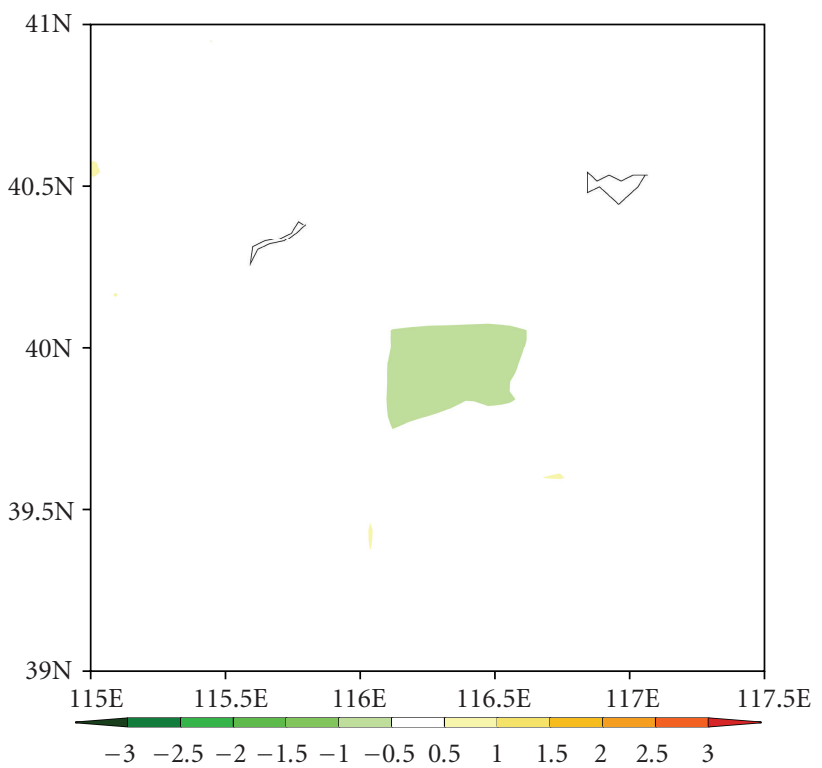

(a)

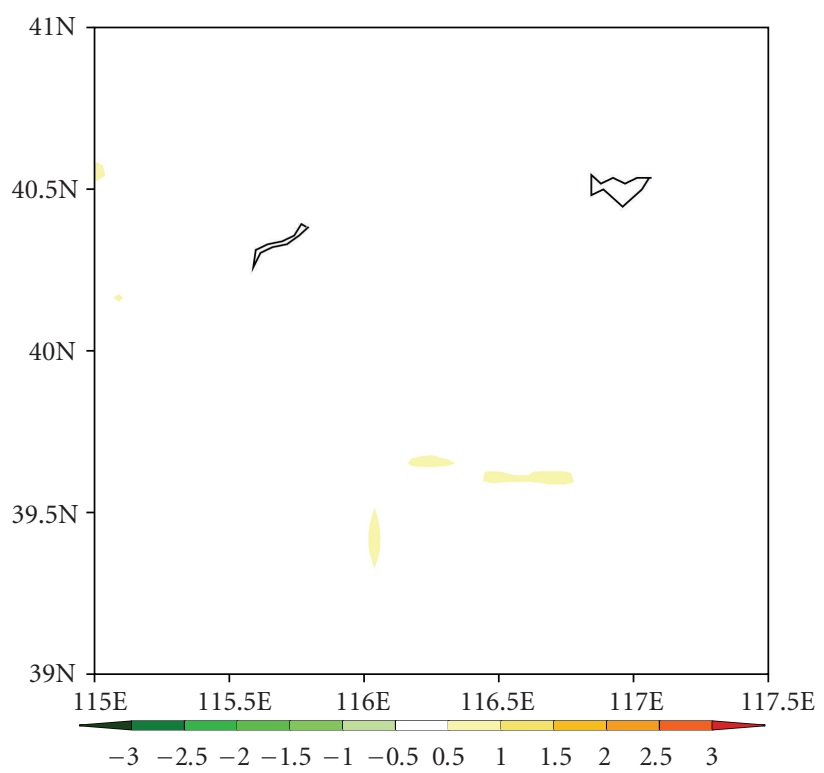

(b)

Figure 10: Same as Figures 9(c) and 9(d)) except for 18Z, July 27, 2008. (a) The difference of $T_{\text {skin }}$ between sensitivity run and the control run, and (b) same as (a) except for $T_{\text {air }}$.

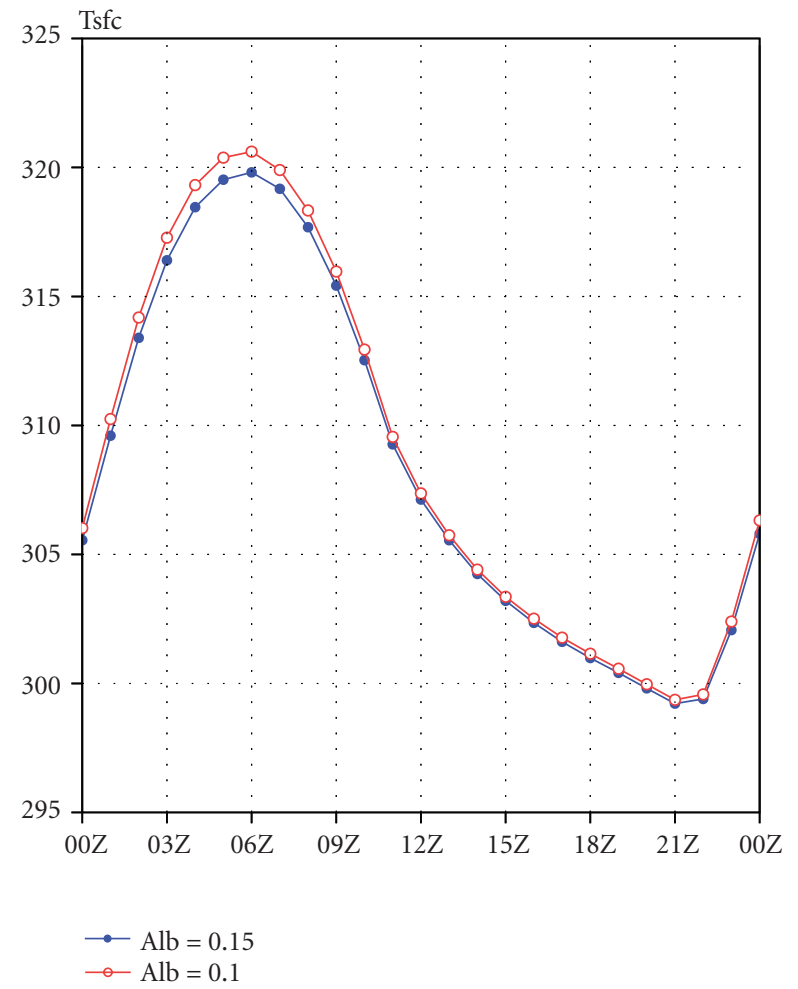

FIGURE 11: Sensitivity study for surface albedo effect on surface skin temperature. $\mathrm{Alb}=0.15$ is the high albedo case when surface albedo is set as 0.15 , and alb $=0.10$ is the low albedo case when the surface albedo is set as 0.10 . The experiment area is over Beijing (39.7$\left.40.1^{\circ} \mathrm{N}, 116.1-116.7^{\circ} \mathrm{E}\right)$. The unit of the $y$-axis is Kelvin $(\mathrm{K})$. that only the direct effect of aerosols is considered here. The indirect effect related to cloud formation and aerosol longwave emission is not discussed and is the subject of ongoing research.

The slightly different responses from $T_{\text {skin }}$ and $T_{\text {air }}$ are particularly important. Traditionally, urban temperature studies use $2-\mathrm{m}$ shelter-based $T_{\text {air }}$ measurements, and it has been reported to be a more nocturnal phenomena [7]. However, $T_{\text {skin }}$ responds to heat more significantly during daytime than at night. This is consistent with recent findings by Shepherd et al. [43] who tried to examine why Houston's UHI could generate a mesoscale circulation during daytime hours. Through land cover change, urban surface albedo and emissivity are reduced $[4,9]$ and thus $T_{\text {skin }}$ is increased. The heated surface stores extra energy and at night, such heat is emitted to warm the air layer closest to the skin surface layer. Therefore, $T_{\text {air }}$ is also found to be warmer than the urban surrounding regions at night.

The sensitivity study approach is an entryway to more robust analysis in the future. We applied an offline radiative transfer model to calculate aerosol directly reduction on surface insolation to avoid using WRF model inbuilt aerosol scheme, which is under development and is linked with cloud formation but has not been fully examined by the users. We did not study aerosol-cloud interaction in this work. In addition, the WRF approach can show how aerosols affect $T_{\text {skin }}$ and how that leads to a change in local mesoscale circulations, and further changes $T_{\text {skin }}$, by using a 4-D (spacetime) atmosphereland surface coupled model. For example, wind is indeed altered due to the change of $T_{\text {skin }}$ (result is not shown). 


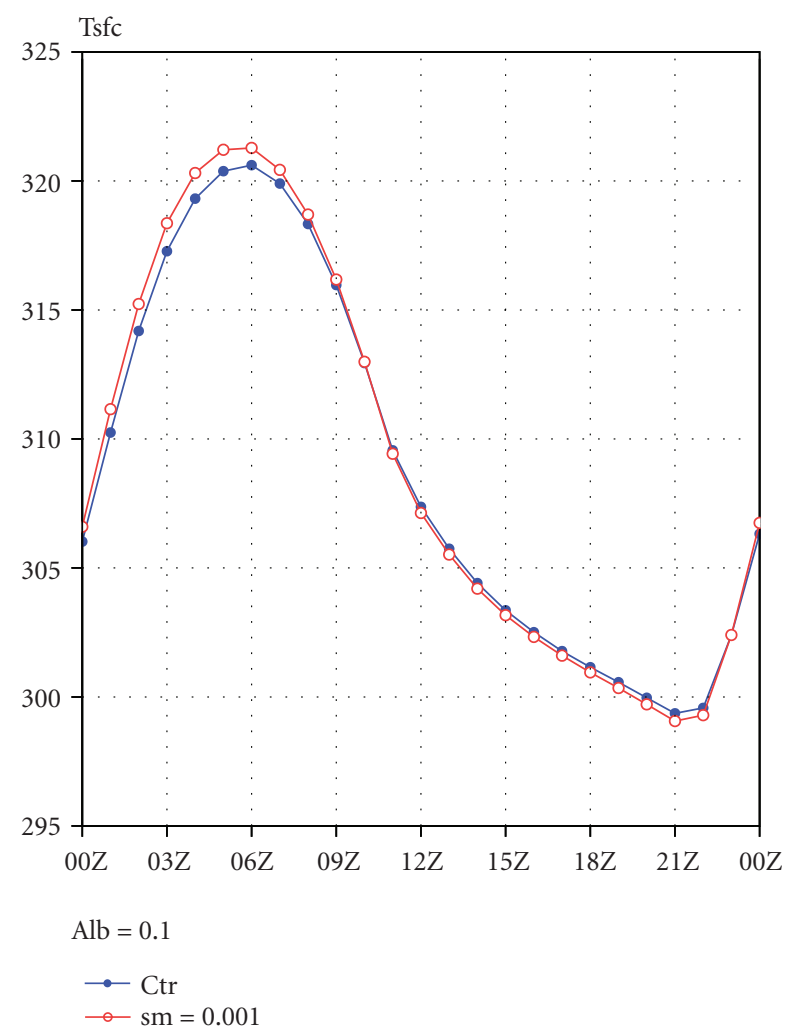

FIGURE 12: Sensitivity study for soil moisture on surface skin temperature. In the control run, initial soil moisture is interpolated from NCEP FNL analysis, and in the sensitivity run, soil moisture in Beijing is set as a small value $\left(0.001 \mathrm{~m}^{3} / \mathrm{m}^{3}\right)$. The surface albedo is set as 0.10 . The experiment area is over Beijing $\left(39.7-40.1^{\circ} \mathrm{N}, 116.1-\right.$ $\left.116.7^{\circ} \mathrm{E}\right)$. The unit of the $y$-axis is Kelvin $(\mathrm{K})$.

Sensitivity experiments on albedo and soil moisture suggest that these land cover related physical processes are as important to $T_{\text {skin }}$ change as aerosol direct effect. The aerosol direct effect appears to reduce surface temperature while albedo and soil moisture reduction increases it. Therefore, in order to predict urban $T_{\text {skin }}$ or UHI, one needs to include all these comparable processes in the model.

The implications of this research are far reaching. At the local to regional scales, proper representation of urban aerosol loading could be critical for diagnosing or forecasting the UHI hazard described by Zhou and Shepherd [8]. In terms of climate analysis, Menon et al. [44] suggested that aerosols, both direct and indirect effects, have a significant impact on many aspects of climate. It is also likely that aerosol variability could explain global brightening/dimming trends in recent decades. Further, the interplay between urban land cover and aerosols is not trivial and must be accounted for in the next generation of global climate models.

\section{Acknowledgments}

This work was funded by NSF Climate Dynamics Program (ATM CDP) (Award no. 0701440), NASA PMM Program
(Award no. NNX07AF39G), and by the Defense Threat Reduction Agency (PI Steve Burian). The authors thank AERONET PIs Hong-Bin Chen and Philippe Goloub for making the measurements public accessible via AERONET site. Thanks for Michael D. King, Tom Eck, and Brent Holben for helpful discussions on AERONET measurements.

\section{References}

[1] H. E. Landsberg, "Man-made climate change," Science, vol. 170, pp. 1265-1274, 1970.

[2] A. J. Arnfield, "An approach to the estimation of the surface radiative properties and radiation budgets of cities," Physical Geography, vol. 3, no. 2, pp. 97-122, 1982.

[3] C. S. B. Grimmond and T. R. Oke, "Heat storage in urban areas: local-scale observations and evaluation of a simple model," Journal of Applied Meteorology, vol. 38, no. 7, pp. 922940, 1999.

[4] M. Jin, R. E. Dickinson, and DA. L. Zhang, "The footprint of urban areas on global climate as characterized by MODIS," Journal of Climate, vol. 18, no. 10, pp. 1551-1565, 2005.

[5] D. M. Yow, "Urban heat islands: observations, impacts, and adaptation," Geography Compass, vol. 1, no. 6, pp. 1227-1251, 2007.

[6] T. R. Oke, "Canyon geometry and the nocturnal urban heat island: comparison of scale model and field observations," Journal of Climatology, vol. 1, no. 3, pp. 237-254, 1981.

[7] T. R. Oke, "The energetic basis of the urban heat island (Symons Memorial Lecture, 20 May 1980)," Quarterly Journal, Royal Meteorological Society, vol. 108, no. 455, pp. 1-24, 1982.

[8] Y. Zhou and J. M. Shepherd, "Atlanta's urban heat island under extreme heat conditions and potential mitigation strategies," Natural Hazards, vol. 52, no. 3, pp. 639-668, 2010.

[9] M. Jin, J. M. Shepherd, and M. D. King, "Urban aerosols and their interac-tion with clouds and rainfall: a case study for New York and Houston," Journal of Geophysical Research, vol. 110, Article ID D10S20, 12 pages, 2005.

[10] G. A. Meehl, C. Tebaldi, G. Walton, D. Easterling, and L. McDaniel, "Relative increase of record high maximum temperatures compared to record low minimum temperatures in the U.S," Geophysical Research Letters, vol. 36, no. 23, Article ID L23701, 2009.

[11] A. Sterl, C. Severijns, H. Dijkstra et al., "When can we expect extremely high surface temperatures?" Geophysical Research Letters, vol. 35, no. 14, Article ID L14703, 2008.

[12] S. A. Changnon, K. E. Kunkel, and B. C. Reinke, "Impacts and responses to the 1995 heat wave: a call to action," Bulletin of the American Meteorological Society, vol. 77, no. 7, pp. 1497-1506, 1996.

[13] B. Menne, "The health impacts of 2003 summer heat-waves. Briefing note for the delegations of the fifty third session of the WHO regional Committee for Europe," WHO Europe, 12pp.

[14] M. Beniston, "The 2003 heat wave in Europe: a shape of things to come? An analysis based on Swiss climatological data and model simulations," Geophysical Research Letters, vol. 31, no. 2, pp. L02202-4, 2004.

[15] S. Cheval, A. Dumitrescu, and A. Bell, "The urban heat island of Bucharest during the extreme high temperatures of July 2007," Theoretical and Applied Climatology, vol. 97, no. 3-4, pp. 391-401, 2009.

[16] J. M. Shepherd, R. Showstack, and M. Jin, "Linkages between the built urban environment and earth's climate system," Eos, vol. 85 , no. 23 , pp. 227-228, 2004. 
[17] M. Jin and J. M. Shepherd, "On including urban landscape in land surface model-how can satellite data help? " Bulletin of the AMS, vol. 86, no. 5, pp. 681-689, 2005.

[18] M. Jin, J. M. Shepherd, and C. Peters-Lidard, "Development of a parameterization for simulating the urban temperature hazard using satellite observations in climate model," Natural Hazards, vol. 43, no. 2, pp. 257-271, 2007.

[19] B. Lamptey, "An analytical framework for estimating the urban effect on climate," International Journal of Climatology, vol. 30, no. 1, pp. 72-88, 2010.

[20] Y. J. Kaufman and I. Koren, "Smoke and pollution aerosol effect on cloud cover," Science, vol. 313, no. 5787, pp. 655-658, 2006.

[21] IPCC, "The Fourth Assessment Report of the Integovernmental Panel on Climate Change. WG1: Climate Change," The Physical Science Basis. Cambridge University Press, pp.996, 2007.

[22] D. Rosenfeld, "Suppression of rain and snow by urban and industrial air pollution," Science, vol. 287, no. 5459, pp. 1793 1796, 2000.

[23] M. Jin and J. M. Shepherd, "Aerosol relationships to warm season clouds and rainfall at monthly scales over east China: urban land versus ocean," Journal of Geophysical Research D, vol. 113, no. 24, Article ID D24S90, 2008.

[24] T. L. Bell and D. Rosenfeld, "Comment on "Weekly precipitation cycles? Lack of evidence from United States surface stations" by D. M. Schultz et al," Geophysical Research Letters, vol. 35, no. 9, Article ID L09803, 2008.

[25] M. K. Kim, . , M. Chin, K. M. Kim, Y. C. Sud, and . , "Atmospheric teleconnection over Eurasia induced by aerosol radiative forcing during boreal spring," Journal of Climate, vol. 19, no. 18, pp. 4700-4718, 2006.

[26] M. Chou and M. J. Suarez, "A solar radiation parameterization for atmosphere studies," Technical Memorandum 104606, NASA, Greenbelt, Md, USA, 1999, vol. 12, 40pages.

[27] B. N. Holben, T. F. Eck, I. Slutsker et al., "AERONET-a federated instrument network and data archive for aerosol characterization," Remote Sensing of Environment, vol. 66, no. 1, pp. 1-16, 1998.

[28] K. C. Seto and J. M. Shepherd, "Global urban land-use trends and climate impacts," Current Opinion in Environmental Sustainability, vol. 1, no. 1, pp. 89-95, 2009.

[29] R. Dickinson, “BATS,” Tech. Rep., NCAR, 1986.

[30] Z. Wan, "A generalized split-window algorithm for retrieving land-surface temperature from space," IEEE Transactions on Geoscience and Remote Sensing, vol. 34, no. 4, pp. 892-905, 1996.

[31] K. Wang, Z. Wan, P. Wang, M. Sparrow, J. Liu, and S. Haginoya, "Evaluation and improvement of the MODIS land surface temperature/emissivity products using ground-based measurements at a semi-desert site on the western Tibetan Plateau," International Journal of Remote Sensing, vol. 28, no. 11, pp. 2549-2565, 2007.

[32] Z. Wan and Z.-L. Li, "Radiance-based validation of the V5 MODIS land-surface temperature product," International Journal of Remote Sensing, vol. 29, pp. 5373-5395, 2008.

[33] T. F. Eck, B. N. Holben, J. S. Reid et al., "Wavelength dependence of the optical depth of biomass burning, urban, and desert dust aerosols," Journal of Geophysical Research D, vol. 104, no. 24, pp. 31333-31349, 1999.

[34] O. Dubovik and M. D. King, "A flexible inversion algorithm for retrieval of aerosol optical properties from Sun and sky radiance measurements," Journal of Geophysical Research D, vol. 105, no. 16, pp. 20673-20696, 2000.
[35] W. C. Skamarock, J. B. Klemp, J. Dudhia et al., "A description of the Advanced Re-search WRF Version 3," NCAR Tech Notes 475+STR, 2008.

[36] F. Chen and J. Dudhia, "Coupling and advanced land surfacehydrology model with the Penn State-NCAR MM5 modeling system. Part I: model implementation and sensitivity," Monthly Weather Review, vol. 129, no. 4, pp. 569-585, 2001.

[37] M. B. Ek, K. E. Mitchell, Y. Lin et al., "Implementation of Noah land surface model advances in the National Centers for Environmental Prediction operational mesoscale Eta model," Journal of Geophysical Research D, vol. 108, no. 22, pp. 1-16, 2003.

[38] H. Kusaka, H. Kondo, Y. Kikegawa, and F. Kimura, "A simple single-layer urban canopy model for atmospheric models: comparison with multi-layer and slab models," BoundaryLayer Meteorology, vol. 101, no. 3, pp. 329-358, 2001.

[39] M. A. Friedl, D. K. McIver, J. C. F. Hodges et al., "Global land cover mapping from MODIS: algorithms and early results," Remote Sensing of Environment, vol. 83, no. 1-2, pp. 287-302, 2002.

[40] M. Jin, "MODIS observed seasonal and interannual variations of atmospheric conditions associated with hydrological cycle over Tibetan Plateau," Geophysical Research Letters, vol. 33, no. 19, Article ID L19707, 2006.

[41] H. Jethva, S. K. Satheesh, J. Srinivasan, and K. K. Moorthy, "How good is the assumption about visible surface reflectance in MODIS aerosol retrieval over Land? A comparison with aircraft measurements over an urban site in India," IEEE Transactions on Geoscience and Remote Sensing, vol. 47, no. 7, part 1, Article ID 4812038, pp. 1990-1998, 2009.

[42] L. Oreopoulos, M. D. Chou, M. Khairoutdinov, H. W. Barker, and R. F. Cahalan, "Performance of Goddard earth observing system GCM column radiation models under heterogeneous cloud conditions," Atmospheric Research, vol. 72, no. 1-4, pp. 365-382, 2004.

[43] J. M. Shepherd, W. M. Carter, M. Manyin, D. Messen, and S. Burian, "The impact of urbanization on current and future coastal convection: a case study for Houston," Environment And Planning B, vol. 37, no. 2, pp. 284-304, 2010.

[44] S. Menon, N. Unger, D. Koch et al., "Aerosol climate effects and air quality impacts from 1980 to 2030," Environmental Research Letters, vol. 3, no. 2, Article ID 024004, 12 pages, 2008. 

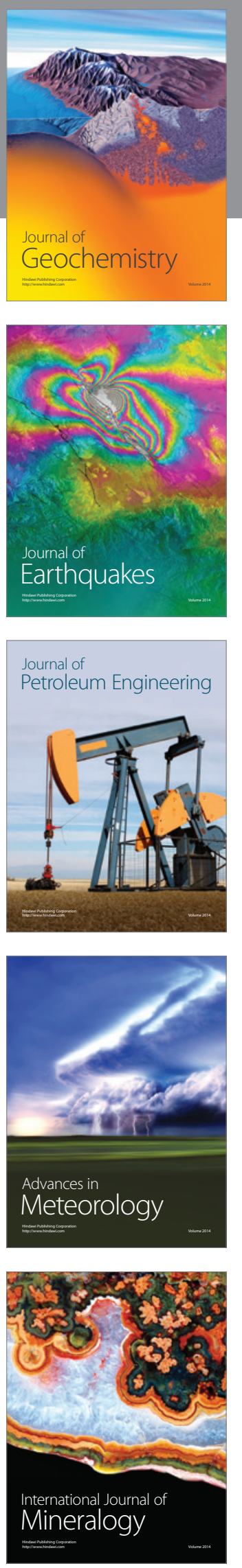
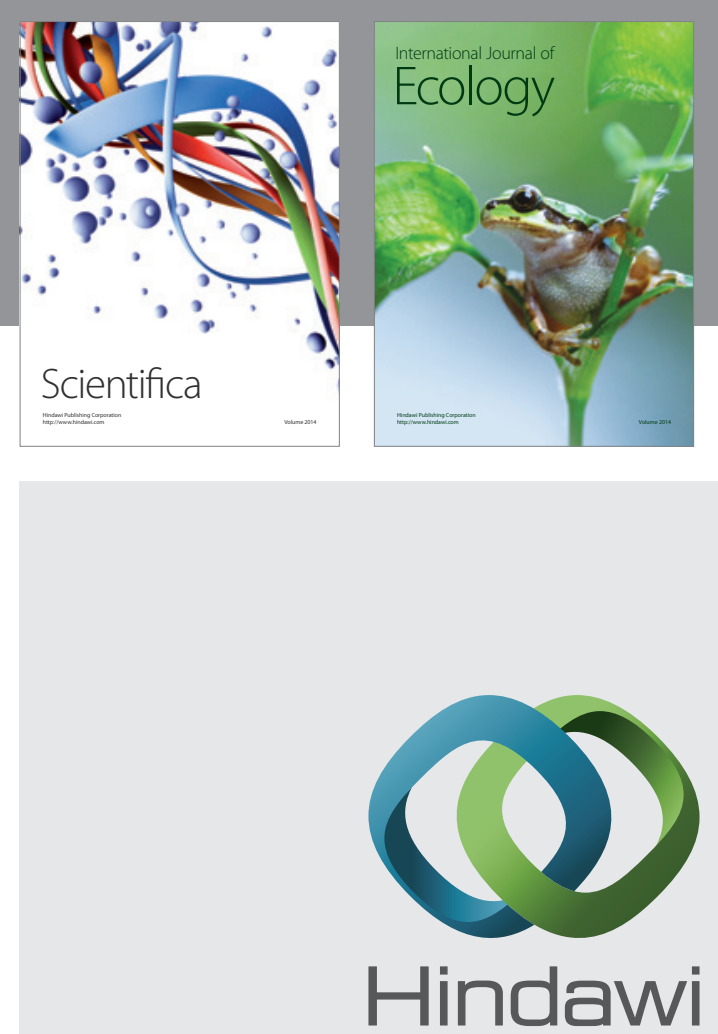

Submit your manuscripts at http://www.hindawi.com
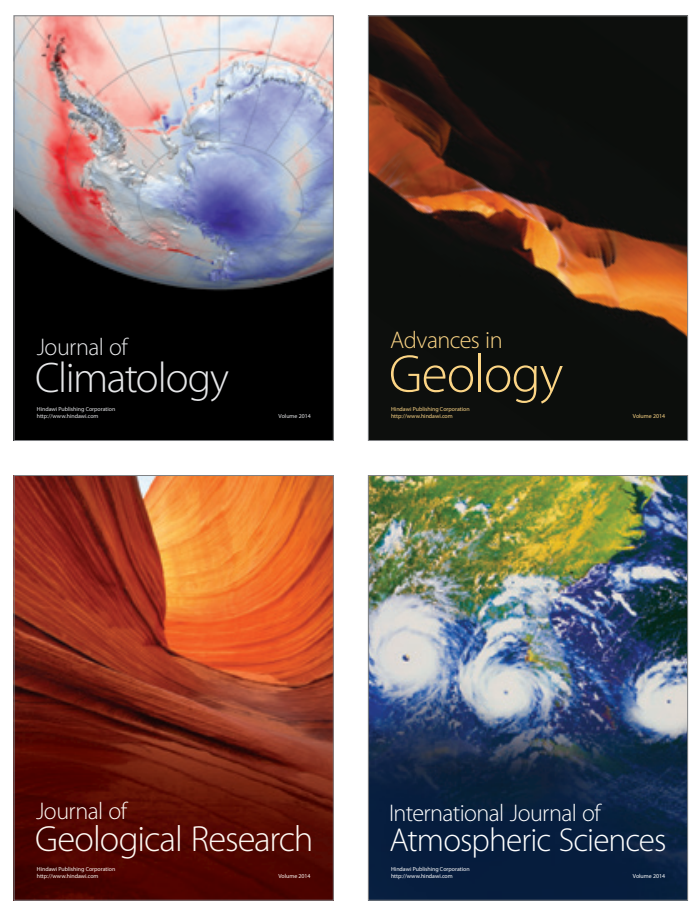
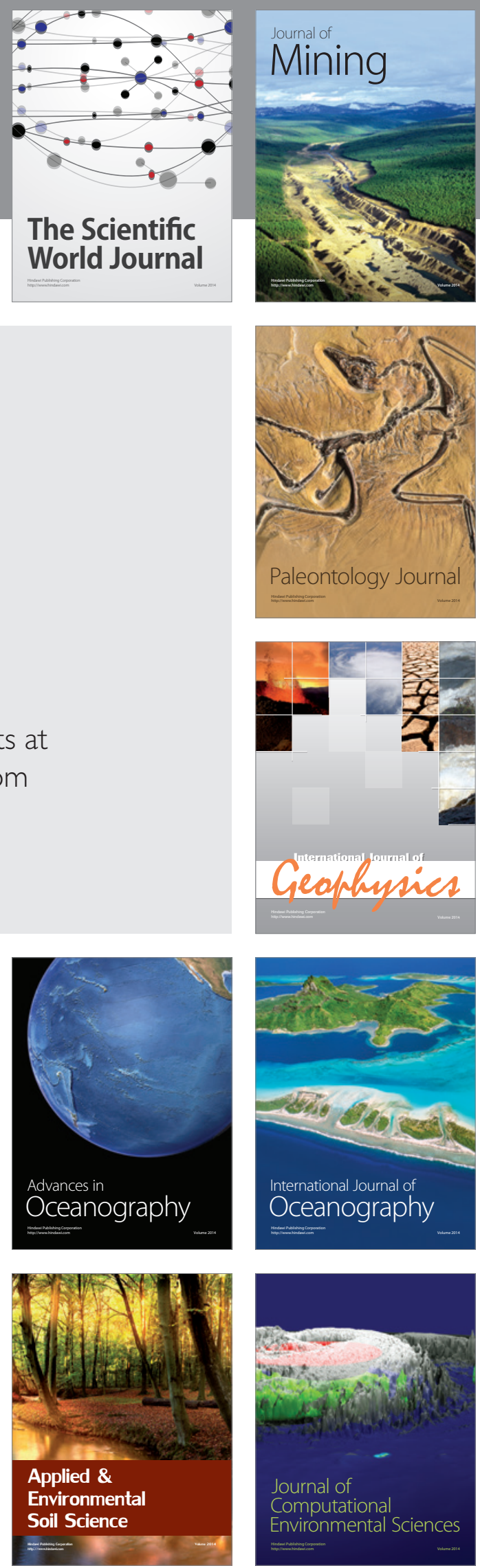